\title{
An Integrated Location-Inventory Model for a Spare Part's Supply Chain Considering Facility Disruption Risk and $\mathrm{CO}_{2}$ Emission
}

\author{
Rubayet Karim ID, Koichi Nakade iD \\ Nagoya Institute of Technology (Japan) \\ rubayet26@gmail.com,nakade@nitech.ac.jp
}

Received: July 2020

Accepted: October 2020

\begin{abstract}
:
Purpose: Managing the inventory of spare parts is very difficult because of the stochastic nature of part's demand. Also, only controlling the inventory of the spare part is not enough; instead, the supply chain of the spare part needs to be managed efficiently. Moreover, every organization now aims to have a resilient and sustainable supply chain to overcome the risk of facility disruption and to ensure environmental sustainability. This paper thus aims to establish a model of inventory-location relating to the resilient supply chain network of spare parts.
\end{abstract}

Design/methodology/approach: First, applying queuing theory, a location-inventory model for a spare parts supply chain facing a facility disruption risk and has a restriction for $\mathrm{CO}_{2}$ emission, is developed. The model is later formulated as a non-linear mixed-integer programming problem and is solved using MATLAB.

Findings: The model gives optimal decisions about the location of the warehouse facility and the policy of inventory management of each location selected. The sensitivity analysis shows that the very low probability of facility disruption does not influence controlling the average emission level. However, the average emission level certainly decreases with the increment of the disruption probability when the facility disruption probability is significant.

Practical implications: Using this model, based on the cost and emission parameters and the likelihood of facility disruption, the spare part's manufacturer can optimize the total average cost of the spare part's supply chain through making a trade-off between productions, warehouse selection, inventory warehousing and demand allocation.

Originality/value: Previous research focuses only on developing a framework for designing an efficient spare parts planning and control system. The inventory-location model for spare parts is not addressed in the sense of risk of facilities disturbance and emission. This research first time jointly considered the probabilistic facility disruption risk and carbon emission for modeling the spare part's supply chain network.

Keywords: spare part's supply chain network, facility disruption probability, $\mathrm{CO}_{2}$ emission, location-inventory problem, queuing theory

\section{To cite this article:}

Karim, R., \& Nakade, K. (2021). An integrated location-inventory model for a spare part's supply chain considering facility disruption risk and $\mathrm{CO}_{2}$ emission. Journal of Industrial Engineering and Management, 14(2), 87-119. https://doi.org/10.3926/jiem.3250 


\section{Introduction}

Organizations have traditionally handled delivery and storage decisions separately, in part because of the difficulty of combining them (Mak \& Shen, 2009). Also, storage and distribution tactical and organizational decisions are regarded separately from strategic decisions regarding the location of facilities and network architecture (Mak \& Shen, 2009). Shen, Coullard and Daskin (2003), Daskin, Coullard and Shen (2002), and Candas and Kutanoglu (2007) have revealed that disregarding inventory effects in facility location decisions can lead to suboptimal logistics network designs. It is also a challenging task to combine facility location decisions with inventory management and distribution decisions, particularly taking into account the risk of facility disruption and environmental sustainability.

Inventory management and facility location problems are the two most exceptional problems in supply chain optimization that have noticeable impacts on the well-organized design of supply chain networks (Gunasekaran, Patel \& Tirtiroglu, 2001; Stevens, 1989). Problems about the location of facilities, as strategic measures, involve deciding the optimal number of open plants and their locations (Dehghani \& Taki, 2019). On the other hand, issues with inventory management consider the responsiveness of the systems in terms of product availability as tactical decisions (Dehghani \& Taki, 2019). Now considering the integrated model of both decisions can lead to better solutions in the light of previous speeches (Diabat, Battaïa \& Nazzal, 2015; Ramezani \& Naderi, 2018).

Most manufacturing or service industries depend on high-value capital assets available to deliver their services or manufacture their goods (Driessen, Arts, van Houtum, Rustenburg \& Huisman, 2015). Companies in these sectors use capital assets in their main operations, and thus, downtime can among others result in (i) lost revenues (e.g., the shutdown of machines in a fabricating environment), (ii) customer frustration and potential related charges (e.g., interruption in airline service or public transportation service) or (iii) community security risk (e.g., interruption in power plants and martial settings) (Driessen et al., 2015). The adverse consequences of downtimes are typically very costly (Driessen et al., 2015).

Since capital assets are important for the operational processes of the businesses involved, there is a need to reduce the lost time for the assets (Driessen et al., 2015). In general, system stoppage or downtime is divided into; (i) diagnosis and maintenance time, (ii) maintenance interruption due to the lack of the required diagnostic and maintenance resources (Driessen et al., 2015). High spare parts accessibility is essential because it affects the maintenance delay (Driessen et al., 2015). On the other hand, the demand for parts may be extremely rare and difficult to predict, and specific spare parts costs can be very high (Huiskonen, 2001). The above-mentioned characteristics generate pressures for streamlining the spare part's logistics system.

Generally, a producer may think that if demand levels are low, shipping directly from the plant to the consumer will often be better rather than storing inventory in warehouses (Mak \& Shen, 2009). However, as discussed above in many applications (especially in spare parts systems), the customers are sensitive to response times (Mak \& Shen, 2009). It is then advantageous to store inventories in warehouses located far from the factory, close to customers. (Mak \& Shen, 2009). Caglar, Li and Simchi-Levi (2004) note that such a system is ideal for spare parts system where warehouses with the inventory of spare parts and technicians are located near customers. For example, products are shipped to customers from nearby storage locations as required in IBM's multi-echelon service parts network (Cohen, Kleindorfer \& Lee, 1989; Kutanoglu, 2008).

Despite the effect that spare parts management has on companies' global efficiency, the majority of conventional literature has not concentrated on the underlying supply chain network of spare parts (Tapia-Ubeda, Miranda, Roda, Macchi \& Durán, 2020). Consequently, issues related to the supply chain and supply chain network are assumed to be given and fixed for most of the research analysis conducted in the spare parts management literature (Huiskonen, 2001; Martin, Syntetos, Parodi, Polychronakis \& Pintelon, 2010; Wagner, Jönke \& Eisingerich, 2012; Li, Cheng, Hu, Zhou, Ma \& Lim, 2019; Liu, Liu \& Deng, 2020). However, the underlying supply chain network for spare parts, which supports the entire operation of spare parts (e.g., distribution, inventories, warehousing), may have a substantial impact on the performance of spare parts management and the results of the company (Cavalieri, Garetti, Macchi \& Pinto, 2008; Hu, Boylan, Chen \& Labib, 2018). Thus, the main feature of this paper is to establish an inventory-location model relating to the spare parts supply chain 
network. Past research focuses primarily on creating a structure for the creation of an effective method of preparation and management of spare parts.

Nowadays, the criteria for sustainability and resiliency compel the manufacturing firm to develop an effective spare part's supply chain network to support the production or service operations. The spare part's supply chain network is vital for aircraft manufacturers (Wheatley, 2014), steel pipe product manufacturers (Tapia-Ubeda et al., 2020), semiconductor equipment manufacturers (Şen, Bhatia \& Doğan, 2010), etc. The general modeling framework is specified for three inventory control policies, i.e. (s, Q), (R, s, S), (S-1, S), commonly used in industrial settings for the management of spare parts (Tapia-Ubeda et al., 2020). In this paper, continuous review (s, Q) policy is considered for modeling the spare part's supply chain network. We consider a supply chain network comprising of manufacturing plants, warehouses, and demand centers. The manufacturing plants and warehouses belong to a manufacturer of spare parts, and the demand centers belong to a retailer who buys the manufacturer's spare parts frequently to meet the end customer's demand. The classic example would be a producer of computer semiconductor who regularly supplies his product to a manufacturer of computer (located at different locations). The computer manufacturer receives the order of semiconductor as spare parts from computer users when users feel the need for spare semiconductor during the maintenance time of a computer or due to the failure of semiconductor equipment. Therefore, apart from the regular production work order, the semiconductor manufacturer also receives random orders of spare parts from the computer manufacturer and delivers the required spare parts as soon as possible through the use of his warehouses. The manufacturer is at risk for disruption of the manufacturing facility. Due to a natural disaster or a man-made action, the designated manufacturing plant may be interrupted at any time. If the designated manufacturing plant is disrupted, the alternative plant is utilized for production and delivery to the assigned warehouses. The spare part's demand and the delivery lead time from the manufacturing plant to the warehouse are uncertain. The warehouse inventory level of the manufacturer is modeled using queuing theory, and finally, the optimization problem is formulated as a mixed-integer nonlinear programming problem. The objective is to develop a location-inventory model for a spare part's manufacturer that minimizes the overall system expenses by optimizing the warehouse location, demand center assignments, and inventory control decisions.

The remainder of the paper is structured as follows. A concise summary of the literature is given in section 2 . The development of the mathematical model, including assumptions, notations, analysis, etc., is written in section 3. Section 4 addresses a numerical comparison with an examination of the sensitivity. Lastly, there is a summary of findings, managerial insights, and some directions for future research in section 5 .

\section{Literature Review}

Nowadays, many business decisions are taken together instead of independently to boost supply chain efficiency and combining facility location, inventory management, and routing problems, and solving them together is standard practice (Melo, Nickel \& Saldanha-Da-Gama, 2009). Location-inventory problems are first suggested in the literature by Daskin et al. (2002) and Shen et al. (2003), and they are thoroughly explored in many directions later. Location-inventory models, for example, are extended to take into account different inventory control strategies (Berman, Krass \& Tajbakhsh, 2012), product attributes (e.g., perishable products, seasonal products, replaceable products, etc.) (Dai, Aqlan, Zheng \& Gao, 2018; Farahani, Shavandi \& Rahmani, 2017), third-party logistics (Arabzad, Ghorbani \& Tavakkoli-Moghaddam, 2015), lateral transshipment (Meissner \& Senicheva, 2018), and correlated or uncertain demands (Diabat, Dehghani \& Jabbarzadeh, 2017; Shahabi, Unnikrishnan, Jafari-Shirazi \& Boyles, 2014). The location-inventory problem has only attracted scholars' attention in the last few years.

Under uncertainty, in the design of supply chain networks, consistent with a classification proposed by Tang (2006), risks from the supply chain may be categorized into operational and disruptive risks depending on the source of uncertainty. Operational risk refers to those recurring risks such as uncertainties of supply and demand, which are inherent in supply chains. The risk of disruption usually involves external disruptions caused by natural disasters or a man-made action (Ivanov, Pavlov, Dolgui, Pavlov \& Sokolov, 2016). Large man-made or natural disasters such as hurricanes, terrorist attacks, earthquakes, and economic crises may impact supply chain networks (Govindan, 
Fattahi \& Keyvanshokooh, 2017). These disturbances, however, typically have a low probability of occurrence, but their effect on the supply chain network is prominent (Govindan et al., 2017).

Another critical problem explored in the literature on the design of the supply chain network is the disruption of facilities (Rayat, Musavi \& Bozorgi-Amiri, 2017). From a traditional standpoint, it is assumed that present facilities are always available to use, but in practice, some facilities may not be accessible due to the risk of disturbances (Rayat et al., 2017). These operational disturbances may occur due to different causes such as recession and strikes, power disruptions, maintenance breaks, etc. (Rayat et al., 2017). These risks can lead to both negative financial and operational impacts like high travel costs, delays in orders, shortages in inventories, etc. (Li, Guo, Wang \& Fu, 2013). Disruptions in the supply chain have a major effect on the organization's performance. Consequently, some effective supply chain strategies must be implemented to sketch a network with minimal cost and risk. To minimize the costs of failure and the risk of disruption, the logistic system provider should design a robust network (Rayat et al., 2017).

According to Cruz (2013) and Gold, Seuring and Beske (2010), growing recognition of the need for environmental conservation and sustainability, enables the government, customers, local communities, and stakeholder organizations to put pressure on companies to efficiently integrate sustainability concerns into their supply chain management practices. Now, one of the most crucial criteria for determining a company's integrity is environmental sustainability at every point of the supply chain (Kumar, Choudhary, Babu, Kumar, Goswami \& Tiwari, 2017). As an example of advocacy group public awareness campaigns, many companies like Texaco, McDonald's, Nestle, Shell, Monsanto, and Mitsubishi have suffered reputational and revenue losses (Svendsen, Boutilier, Abbott \& Wheeler, 2001). From this necessity, the researcher is now incorporating environmental emissions into the traditional location-inventory supply chain network model. For example, the carbon emission constrained location-inventory models have been studied by Al Dhaheri and Diabat (2011), Diabat and Al-Salem (2015), and Dai et al. (2018).

Disruption and environment sustainability both need to be addressed in the design of a robust and efficient supply chain. Disruption and environmental sustainability are interrelated. For instance, in the make-to-order manufacturing system, spontaneous disturbance in product quality induces to manufacture more than the actual requirement to prevent deficit of consumer demand, and this excessive output would generate more carbon emissions. Quite surprisingly, apart from this negative outcome, the disruption also has a positive environmental impact. The latest example is operational disruption due to the COVID-19 outbreak, which has a significant impact on factory shutdown and airline scheduling cancellation, in most parts of the world. As a result, the major collapse in factory production and the cancelation of transportation on international routes are helping to ensure environmental sustainability by reducing $\mathrm{CO}_{2}$ emissions even though it ultimately causes an economic crisis.

A full literature review can be found in Farahani, Rashidi Bajgan, Fahimnia and Kaviani (2015) on the modeling of a location-inventory problem in the supply chain. However, Table 1 shows a brief review of the literature relevant to our research on the problem of inventory-location. How our proposed study differs from the previous research can be easily realized in Table 1 .

Previously, most researchers consider storage or distribution center disruption risk only (Liu, Wang \& Ouyang, 2017; Rayat et al., 2017; Fattahi \& Govindan, 2018; Azadeh \& Arani 2016; Rabbani, Aliabadi, Heidari \& Farrokhi-Asl, 2017). Disruption may also occur in the manufacturing plant. For example, the deadly coronavirus (COVID-19 epidemic) recently hits China's Wuhan city. Many world-renowned automotive and automotive parts companies in this city have their factory. The spread of the virus among this city's mass populations forced all major manufacturing plants to be shut down.

The spare part's supply chain system may confront facility disruption risk and may have an emission barrier. Furthermore, the spare part's inventory is expensive, and in terms of financial worth, the spare part's inventory reduction can generate high business value. But at the same time, the reduction in inventory could create a stock-out situation of the spare parts, which ultimately makes a bad market image for the manufacturer of the spare parts. Since failure to get the required spare parts on time can result in a significant financial loss for the 
spare part's user. Disruption, $\mathrm{CO}_{2}$ emission, etc., are explicitly discussed for a Bio-mass supply chain model (Liu et al., 2017; Fattahi \& Govindan, 2018; Azadeh \& Arani, 2016; Ahranjani et al., 2020). Also, the source of emissions in a network is considered either from production and transportation (Kumar et al., 2017; Fattahi \& Govindan, 2018; Ahranjani et al., 2020) or from transportation and warehousing (Peng et al., 2016; Al Dhaheri \& Diabat, 2011).

\begin{tabular}{|c|c|c|c|c|c|c|}
\hline Paper & $\begin{array}{l}\text { Assumption } \\
\text { regarding the } \\
\text { customer } \\
\text { demand }\end{array}$ & $\begin{array}{l}\text { Consideration } \\
\text { of unsatisfied } \\
\text { customer } \\
\text { demand }\end{array}$ & $\begin{array}{l}\text { Disruption } \\
\text { risk type }\end{array}$ & $\begin{array}{l}\text { Source of } \\
\text { emission }\end{array}$ & $\begin{array}{l}\text { Modeling } \\
\text { approach }\end{array}$ & Decision variables \\
\hline $\begin{array}{l}\text { Peng Ablanedo- } \\
\text { Rosas \& Fu } \\
(2016)\end{array}$ & $\begin{array}{l}\text { Fixed and } \\
\text { decided based on } \\
\text { demand forecast }\end{array}$ & Lost sales & - & $\begin{array}{l}\text { Transportation } \\
\text { and } \\
\text { warehousing } \\
\text { operations }\end{array}$ & $\begin{array}{l}\text { Mixed integer } \\
\text { linear } \\
\text { programming } \\
\text { model }\end{array}$ & $\begin{array}{l}\text { The procurement } \\
\text { quantity from } \\
\text { factories to the points } \\
\text { of sales and the } \\
\text { transportation cost } \\
\text { from the factories to } \\
\text { the point of sales. }\end{array}$ \\
\hline Liu et al.(2017) & Fixed & $\begin{array}{l}\text { All demands are } \\
\text { satisfied and no } \\
\text { unsatisfied } \\
\text { demand }\end{array}$ & $\begin{array}{l}\text { Collection } \\
\text { facility } \\
\text { disruption }\end{array}$ & - & $\begin{array}{l}\text { Reliable } \\
\text { incapacitated fixed } \\
\text { charge location } \\
\text { model }\end{array}$ & $\begin{array}{l}\text { Biomass shipment } \\
\text { and inventory } \\
\text { holding quantity, and } \\
\text { facility location } \\
\text { decisions. }\end{array}$ \\
\hline $\begin{array}{l}\text { Rayat et } \\
\text { al.(2017) }\end{array}$ & Stochastic & $\begin{array}{l}\text { Partial } \\
\text { backordering with } \\
\text { lost sales }\end{array}$ & $\begin{array}{l}\text { Distribution } \\
\text { center } \\
\text { disruption }\end{array}$ & - & $\begin{array}{l}\text { Reliable } \\
\text { incapacitated fixed } \\
\text { charge location } \\
\text { model }\end{array}$ & $\begin{array}{l}\text { Facility location, } \\
\text { ordering, and routing } \\
\text { decisions. }\end{array}$ \\
\hline $\begin{array}{l}\text { Fattahi \& } \\
\text { Govindan (2018) }\end{array}$ & Fixed & Lost sales & $\begin{array}{l}\text { Storage facility } \\
\text { disruption }\end{array}$ & $\begin{array}{l}\text { Biofuel } \\
\text { production } \\
\text { and } \\
\text { Biomass \& } \\
\text { biofuel }\end{array}$ & $\begin{array}{l}\text { A bi-objective } \\
\text { mixed-integer } \\
\text { nonlinear } \\
\text { programming } \\
\text { (MINLP) } \\
\text { model }\end{array}$ & $\begin{array}{l}\text { Facility location, } \\
\text { production, } \\
\text { transportation, and } \\
\text { inventory decisions. }\end{array}$ \\
\hline $\begin{array}{l}\text { Azadeh \& Arani } \\
\text { (2016) }\end{array}$ & \begin{tabular}{|l|} 
Biodiesel price, \\
fossil fuel price, \\
fuel \\
consumption of \\
bio-automobile, \\
social effect of \\
air pollution, \\
and government \\
policy \\
dependent \\
demand
\end{tabular} & Lost sales & $\begin{array}{l}\text { 1.Disruption } \\
\text { in connection } \\
\text { between } \\
\text { biomass field, } \\
\text { bio-refineries, } \\
\text { and demand } \\
\text { center } \\
\text { 2.Disruption } \\
\text { in biomass } \\
\text { field }\end{array}$ & - & $\begin{array}{l}\text { A hybrid system } \\
\text { dynamics- } \\
\text { stochastic } \\
\text { mathematical } \\
\text { Programming } \\
\text { approach }\end{array}$ & $\begin{array}{l}\text { Facility location, } \\
\text { technology, } \\
\text { production, inventory, } \\
\text { and transportation } \\
\text { decisions. }\end{array}$ \\
\hline $\begin{array}{l}\text { Ahranjani, } \\
\text { Ghaderi, Azadeh } \\
\text { \& Babazadeh, } \\
(2020)\end{array}$ & Deterministic & $\begin{array}{l}\text { Demands are } \\
\text { satisfied }\end{array}$ & $\begin{array}{l}\text { Disruption in } \\
\text { biomass } \\
\text { feedstock yield }\end{array}$ & $\begin{array}{l}\text { Biomass } \\
\text { production } \\
\text { and } \\
\text { transportation }\end{array}$ & $\begin{array}{l}\text { A hybrid robust } \\
\text { stochastic- } \\
\text { possibilistic } \\
\text { programming } \\
\text { approach }\end{array}$ & $\begin{array}{l}\text { Facility location, } \\
\text { capacity and } \\
\text { technology of bio } \\
\text { refineries, } \\
\text { transportation } \\
\text { modes, Biomass } \\
\text { shipments, inventory } \\
\text { levels, production, } \\
\text { and import amounts } \\
\text { decisions. }\end{array}$ \\
\hline
\end{tabular}




\begin{tabular}{|c|c|c|c|c|c|c|}
\hline Paper & $\begin{array}{l}\text { Assumption } \\
\text { regarding the } \\
\text { customer } \\
\text { demand }\end{array}$ & $\begin{array}{l}\text { Consideration } \\
\text { of unsatisfied } \\
\text { customer } \\
\text { demand }\end{array}$ & $\begin{array}{l}\text { Disruption } \\
\text { risk type }\end{array}$ & $\begin{array}{l}\text { Source of } \\
\text { emission }\end{array}$ & $\begin{array}{l}\text { Modeling } \\
\text { approach }\end{array}$ & Decision variables \\
\hline $\begin{array}{l}\text { Kumar et al. } \\
\text { (2017) }\end{array}$ & $\begin{array}{l}\text { Selling price } \\
\text { dependent } \\
\text { demand }\end{array}$ & No lost sales & $\begin{array}{l}\text { Supply } \\
\text { disruption }\end{array}$ & $\begin{array}{l}\text { Production } \\
\text { and } \\
\text { transportation }\end{array}$ & \begin{tabular}{|l|} 
A Pareto-based \\
multi objective \\
evolutionary \\
algorithm-non- \\
dominated sorting \\
genetic algorithm- \\
II(NSGA-II)
\end{tabular} & $\begin{array}{l}\text { Production, inventory } \\
\text { holding, and delivery } \\
\text { quantity of the } \\
\text { supplier and the } \\
\text { manufacturer. } \\
\text { Inventory holding and } \\
\text { selling quantity of the } \\
\text { retailer. Level of social } \\
\text { relationship between } \\
\text { supplier, manufacturer, } \\
\text { and the retailer. }\end{array}$ \\
\hline $\begin{array}{l}\text { Al Dhaheri \& } \\
\text { Diabat (2011) }\end{array}$ & Stochastic & No lost sales & - & $\begin{array}{l}\text { Transportation } \\
\text { and } \\
\text { warehousing } \\
\text { operations }\end{array}$ & \begin{tabular}{|l|} 
A multiple \\
product \\
capacitated \\
inventory-location \\
supply chain \\
model
\end{tabular} & $\begin{array}{l}\text { Re-order time, re- } \\
\text { order quantity, safety } \\
\text { stock quantity in each } \\
\text { selected facility, and } \\
\text { facility location } \\
\text { decisions. }\end{array}$ \\
\hline $\begin{array}{l}\text { Dehghani \& } \\
\text { Taki (2019) }\end{array}$ & Stochastic & Back order & - & - & $\begin{array}{l}\text { A mixed integer } \\
\text { nonlinear } \\
\text { programming } \\
\text { model (MINLP) } \\
\text { and Queuing } \\
\text { theory }\end{array}$ & $\begin{array}{l}\text { Facility location and } \\
\text { inventory control } \\
\text { decisions. }\end{array}$ \\
\hline $\begin{array}{l}\text { Sadjadi, Makui } \\
\text { Dehghani \& } \\
\text { Pourmohammad } \\
\text { (2016) }\end{array}$ & Stochastic & Lost sales & - & - & $\begin{array}{l}\text { A mixed integer } \\
\text { nonlinear } \\
\text { programming } \\
\text { model (MINLP) } \\
\text { and Queuing } \\
\text { theory }\end{array}$ & $\begin{array}{l}\text { Facility location and } \\
\text { inventory control } \\
\text { decisions. }\end{array}$ \\
\hline $\begin{array}{l}\text { Rabbani et al. } \\
(2017)\end{array}$ & Stochastic & Lost sales & $\begin{array}{l}\text { Distribution } \\
\text { center } \\
\text { disruption }\end{array}$ & - & $\begin{array}{l}\text { A mixed integer } \\
\text { nonlinear } \\
\text { programming } \\
\text { model (MINLP) } \\
\text { and Queuing } \\
\text { theory }\end{array}$ & $\begin{array}{l}\text { Facility location and } \\
\text { inventory control } \\
\text { decisions. }\end{array}$ \\
\hline $\begin{array}{l}\text { Tapia-Ubeda et } \\
\text { al. }(2020)\end{array}$ & Stochastic & $\begin{array}{l}\text { Demands are } \\
\text { satisfied }\end{array}$ & - & - & $\begin{array}{l}\text { A generic network } \\
\text { optimization } \\
\text { modelling } \\
\text { structure }\end{array}$ & $\begin{array}{l}\text { Facility location and } \\
\text { inventory control } \\
\text { decisions. }\end{array}$ \\
\hline $\begin{array}{l}\text { Diabat et al. } \\
\text { (2017) }\end{array}$ & Stochastic & Lost sales & - & - & $\begin{array}{l}\text { A hybrid solution } \\
\text { algorithm based } \\
\text { on simulated } \\
\text { annealing and } \\
\text { direct search } \\
\text { method and } \\
\text { Queuing theory }\end{array}$ & $\begin{array}{l}\text { Facility location and } \\
\text { inventory control } \\
\text { decisions. }\end{array}$ \\
\hline This study & Stochastic & $\begin{array}{l}\text { Lost sales due to } \\
\text { empty ware house }\end{array}$ & $\begin{array}{l}\text { Manufacturing } \\
\text { plant } \\
\text { disruption }\end{array}$ & \begin{tabular}{|l|} 
Production, \\
transportation \\
and \\
warehousing \\
operations of \\
spare parts
\end{tabular} & $\begin{array}{l}\text { A mixed integer } \\
\text { nonlinear } \\
\text { programming } \\
\text { model (MINLP) } \\
\text { and Queuing } \\
\text { theory }\end{array}$ & $\begin{array}{l}\text { Facility location and } \\
\text { inventory control } \\
\text { decisions. }\end{array}$ \\
\hline
\end{tabular}

Table 1. Literature review summary 
However, the supply chain location-inventory model of the spare parts in the context of a facility (manufacturing plant) disruption risk and environmental sustainability in terms of carbon emission is not investigated. Moreover, the interaction between the probabilistic facility disruption risk and environmental emission is not being discussed. That's why by considering all possible sources of emission, such as production, transportation, and warehousing, a new location-inventory model of the spare part's supply chain is formulated to fill the existing gap of spare part's supply chain literature. The key contribution of this paper is the joint consideration of the manufacturing facility disruption risk and environmental emission for modeling a spare part's supply chain network where both spare part's demand and delivery lead time are uncertain. The impact of probabilistic facility distuption risk in controlling the average emission level is also shown.

\section{Model Descriptions}

A spare parts supply chain network is considered where consumers seek for spare parts to the demand center. We focus only on non-repairable maintenance spare parts. Demand for a spare part is generated during the preventive maintenance period (when the old component is worn out and not at all usable) or during the corrective maintenance period (the working component is unexpectedly failed during operation).

The demand center places an order at its closest (warehouse) distribution center. The demand centers belong to a seller or a retailer who sells the manufacturer's product. A manufacturer operates the production plants and warehouses. The manufacturer operates two manufacturing plants at different locations. The manufacturer also has an environmental restriction in terms of $\mathrm{CO}_{2}$ emissions.

The designated production site, which is close to the warehouse facilities, also fulfills all warehouses' demands. Any natural disaster or man-made action or machine malfunction may interrupt the operation of the designated manufacturing plant. If the designated plant is disrupted, the manufacturer selects the alternative plant which is reliable and is located very far from the warehouse facilities. For example, recently, every major manufacturing plant in China's city of Wuhan is shut down due to the operational disruption caused by the spread of the coronavirus. As a result, the manufacturer makes sourcing from the other manufacturing plant outside China to address the crisis of demand shortages.

There is a set of fixed locations of demand center denoted by $I$, and each demand center $i \in\{1,2 \ldots I\}$ is only allocated to one opened warehouse. The demands of every demand center $i$ arrive according to a Poisson process with a parameter $\lambda^{i}$, and the demands of the demand centers are independent. On the other hand, there is a set of candidate locations denoted by $K$, where warehouses will be constructed. The notation $\lambda_{k}$ denotes the demand arrival rate in the Poisson distribution for every opened warehouse $k$, where $k \in\{1,2 \ldots K\}$. That is $\lambda_{k}$ is a function of $\lambda^{i}$, and $\lambda_{k}$ is a decision variable (See Figure 2).

Every warehouse manager controls his inventory system by using $\left(s_{k}, Q_{k}\right)$ inventory policy where $Q_{k}>s_{k}$. Based on this policy, each opened warehouse $k$ places an order of $Q_{k}$ at the designated manufacturing plant when the inventory level declines to $s_{k}$. Here, $Q_{k}$ and $s_{k}$ are decision variables. The maximum inventory capacity of a warehouse located in $k$ is $I_{\max }^{k}$. Moreover, each opened warehouse follows First in, First out (FIFO) policy. According to this policy, an order that comes first is delivered first. If the designated manufacturing plant disrupts with probability $q$, the order immediately places at the alternative plant. So, the probability of receiving an order from the alternative manufacturing plant is $q$. Oppositely, the probability of receiving an order from the designated manufacturing plant is $1-q$. The order arrives after a random lead time. This order delivery time follows an exponential distribution with parameter $\mu_{1}$ for the designated plant and $\mu_{2}$ for the alternative plant where $\mu_{1}>\mu_{2}$. So the exponential delivery rate from the manufacturing plant to the opened warehouse $k$ can be denoted as $\mu$ where $\mu=(1-q) \mu_{1}+q \mu_{2}$. If the inventory level of any warehouse $k$ is empty while demand arrives from the demand center, all the unmet demands are considered as lost sales for that assigned warehouse $k$.

The research objective is to design a three-echelon supply chain network that consists of manufacturing plants, warehouses, and demand centers. The proposed supply chain network of a spare parts manufacturer is illustrated in Figure 1. Using queuing theory to model the on-hand inventory levels in warehouses, the proposed model provides the following decisions: 
1. Optimum number and location of warehouses;

2. The optimum allocation of demand centers to the opened warehouses and

3. The optimum $\left(s_{k}, Q_{k}\right)$ inventory control policy for each opened warehouse $k$.

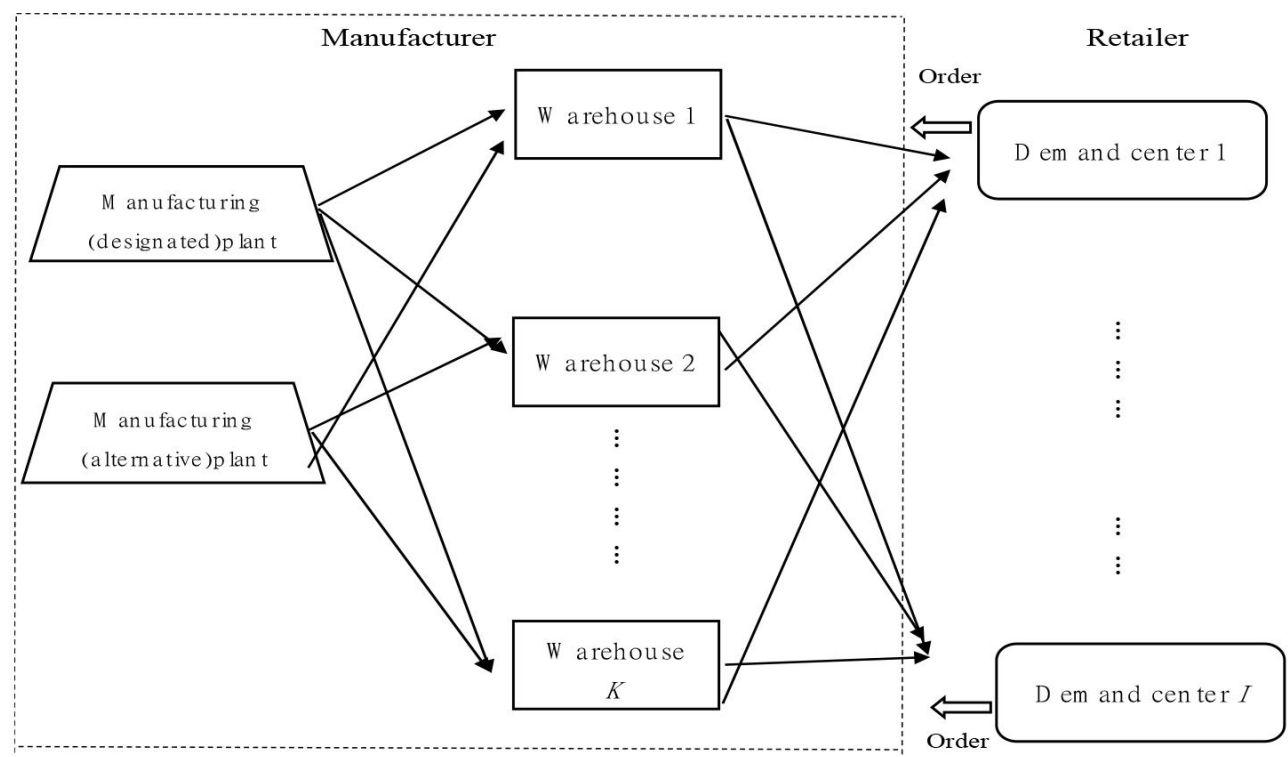

Figure 1. Spare parts supply chain network

A spare parts supply chain network subject to probabilistic facility disruption risk is considered in this research. The objective is to optimize the total supply chain cost of a spare parts manufacturer consisting of the spare parts manufacturing cost, the warehouse setup cost, the transportation cost, the emission cost (due to production, transportation and warehousing), the lost sales cost and the inventory holding cost. In this regard, the manager of a warehouse (k) must make a tradeoff between $\lambda_{k}, s_{k}$, and $Q_{k}$ in such a way that minimizes the cost (see Figure 2).

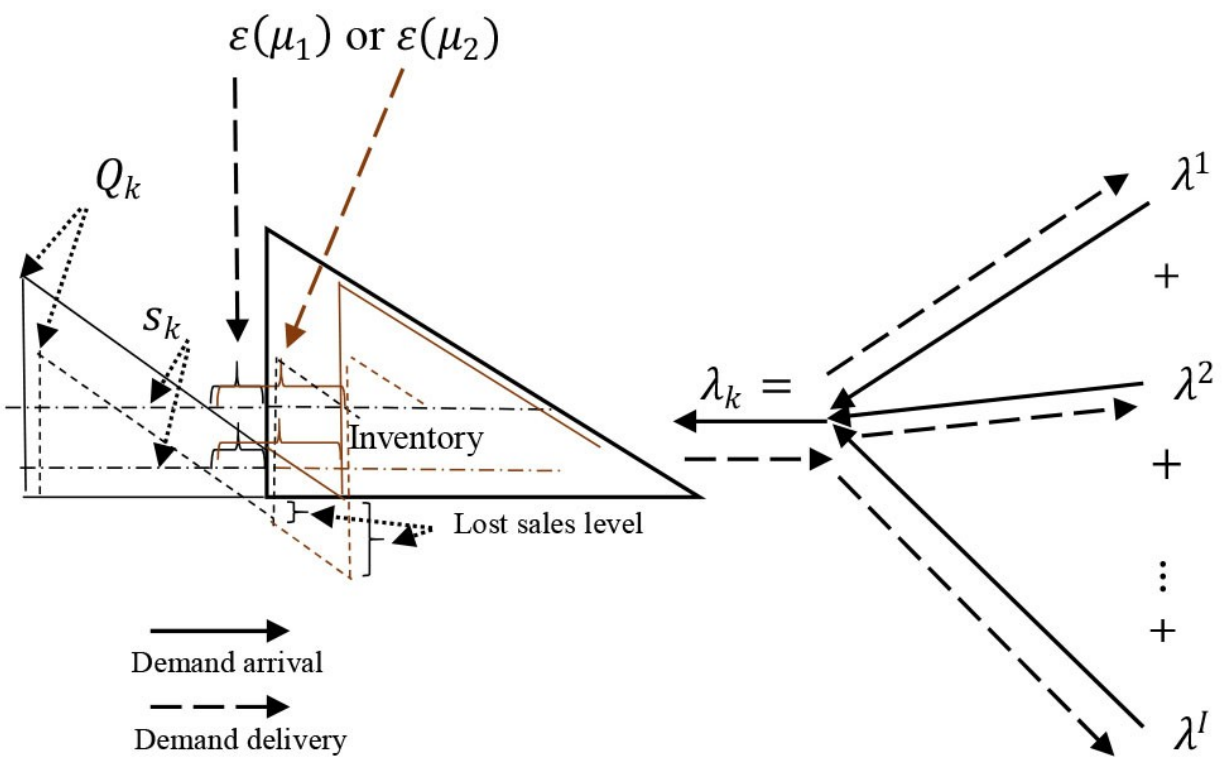

Figure 2. $Q_{k}, s_{k}, \lambda_{k}$ dependent inventory accumulation, and stochastic demand arrival and delivery process in a warehouse $(k)$ 


\begin{tabular}{|c|c|}
\hline \multicolumn{2}{|c|}{ Sets: } \\
\hline K & Set of opened warehouses; $k \in\{1,2 \ldots K\}$ \\
\hline$I$ & Set of demand centers; $i \in\{1,2 \ldots I\}$ \\
\hline \multicolumn{2}{|c|}{ Parameters: } \\
\hline$q$ & The disruption probability of the designated plant \\
\hline$\mu_{1}$ & Average delivery rate (exponential) of the designated plant (average lots per unit time) \\
\hline$\mu_{2}$ & Average delivery rate (exponential) of the alternative plant (average lots per unit time) \\
\hline$\lambda^{i}$ & Average demand rate (lots) of demand center i (Poisson) $\forall i \in I$ \\
\hline$O_{k}$ & Expected number of reorders per unit time by warehouse $k$ \\
\hline$B_{k}$ & Expected number of lost sales (lots) per unit time by warehouse $k$ \\
\hline$Y_{k}$ & The expected amount of production quantity (lots) per unit time by the manufacturing plant. \\
\hline$L_{k}$ & The mean inventory level (lots) of warehouse $k$ \\
\hline$G_{k}$ & The expected shipment quantity (lots) per unit time from the warehouse $k$ to the demand centers $(i)$ \\
\hline$\omega_{k}$ & The average emission level per unit time of warehouse $k\left(\right.$ ton $\left.\mathrm{CO}_{2}\right)$ \\
\hline$\varnothing^{\max }$ & The permissible limit of emission per unit time $\left(\right.$ ton $\left.\mathrm{CO}_{2}\right)$ \\
\hline$I_{\max }^{k}$ & The maximum capacity of inventory of warehouse $k$ \\
\hline$\varphi_{1 k}$ & $\begin{array}{l}\text { The amount of } \mathrm{CO}_{2} \text { emissions generated by the shipment of one unit of spare parts from the designated plant to } \\
\text { the warehouse } k\left(\text { ton } \mathrm{CO}_{2}\right)\end{array}$ \\
\hline$\varphi_{2 k}$ & $\begin{array}{l}\text { The amount of } \mathrm{CO}_{2} \text { emissions generated by the shipment of one unit of spare parts from the alternative plant to } \\
\text { the warehouse } k\left(\text { ton } \mathrm{CO}_{2}\right)\end{array}$ \\
\hline$\varphi_{k i}$ & $\begin{array}{l}\text { The amount of } \mathrm{CO}_{2} \text { emissions generated by the shipment of one unit of spare parts from the warehouse } k \text { to the } \\
\text { demand center } i\left(\operatorname{ton} \mathrm{CO}_{2}\right)\end{array}$ \\
\hline$\delta_{k}$ & The amount of $\mathrm{CO}_{2}$ emissions generated by holding one unit of inventory in warehouse $k$ (ton $\mathrm{CO}_{2}$ ) \\
\hline$\partial_{1}$ & $\begin{array}{l}\text { The amount of } \mathrm{CO}_{2} \text { produced by the production of a single unit of spare parts from the designated manufacturing } \\
\text { plant (ton } \mathrm{CO}_{2} \text { ) }\end{array}$ \\
\hline$\partial_{2}$ & $\begin{array}{l}\text { The amount of } \mathrm{CO}_{2} \text { produced by the production of a single unit of spare parts from the alternative manufacturing } \\
\text { plant (ton } \mathrm{CO}_{2} \text { ) }\end{array}$ \\
\hline \multicolumn{2}{|c|}{ Cost parameters } \\
\hline $\mathrm{C}^{T}$ & The total supply chain cost of the manufacturer \\
\hline$\Omega$ & The warehouse setup cost per unit time \\
\hline$y_{0}$ & Per unit (ton) $\mathrm{CO}_{2}$ emission cost \\
\hline$y_{1}$ & Per unit manufacturing cost \\
\hline$y_{2}$ & Per unit lost sales cost \\
\hline$y_{3}$ & Per unit inventory holding cost \\
\hline$y_{1 k}$ & The cost of transporting one unit of spare parts from the designated plant to the warehouse $k$ \\
\hline$y_{2 k}$ & The cost of transporting one unit of spare parts from the alternative plant to the warehouse $k$ \\
\hline$y_{k i}$ & The cost of transporting one unit of spare parts from the warehouse $k$ to the demand center $i$. \\
\hline \multicolumn{2}{|c|}{ Decision variables } \\
\hline \multicolumn{2}{|c|}{ 1. Binary decision variables } \\
\hline$U_{k}$ & 1 if a warehouse is built in $k, 0$ otherwise; $\forall k \in K$ \\
\hline$V_{k i}$ & 1 if demand center $i$ is allocated to opened warehouse $k, 0$ otherwise; $\forall i \in I, \forall k \in K$ \\
\hline
\end{tabular}




\begin{tabular}{|l|l|}
\hline \multicolumn{2}{|l|}{ 2. Other decision variables } \\
\hline$\lambda_{k}$ & Average demand rate for opened warehouse $k ; \forall k \in K$ \\
\hline$s_{k}$ & Reorder level at opened warehouse $k ; \square k \in K$ \\
\hline$Q_{k}$ & Reorder quantity at opened warehouse $k ; \forall k \in K$ \\
\hline
\end{tabular}

Table 2. Notations

It should be noted here that the study is limited only to the manufacturer of spare parts, and thus, all costs, including the penalty costs due to the demand center's lost sales, are excluded. The notation used in the model is shown in Table 2 above.

\subsection{Warehouse Inventory Level Formulation}

Let $I_{k}(t)$ denotes the on-hand inventory level in warehouse $k$ at time $t$ where the minimum and maximum values of on-hand inventory are 0 and $Q_{k}+s_{k}$, respectively. According to the Poisson process, demand arrivals at warehouses occur at a rate $\lambda_{k}$, and thus, the inter-arrival times of demand at warehouses are distributed exponentially. Ultimately, due to the finite range of inventory level $\left(0\right.$ to $\left.Q_{k}+s_{k}\right)$ at each warehouse, and the memoryless property of exponential distribution, warehouse inventory levels can be defined as states of a Markov chain. Now the inventory level process $\left\{I_{k}(t) ; t \geq 0\right\}$ with the state space of $E_{k}=\left\{0,1,2, \ldots, Q_{k}+s_{k}\right\}$ is a continuous time Markov chain. Now if $z$ and $j$ represent the values (states) of $I_{k}(t)$ then the probability of transition from state $₹$ to $j$ (from time 0 to $t$ ) can be defined as follows

$$
P_{k}(z, j, t)=P\left(I_{k}(t)=j \mid I_{k}(0)=z\right), z, j \in E_{k} .
$$

As $I_{k}(t)$ denotes the on hand inventory level in warehouse $k$ at time $t$ and hence, the steady state probability of getting inventory level $j$ in warehouse $k$ can be defined as follows

$$
P_{k}(j)=\lim _{t \rightarrow \infty} P_{k}(z, j, t) .
$$

The inventory level process can be defined as a birth-death process because the birth-death process is a continuous time Markov chain. According to the birth-death process, in the long run, the rate at which the inventory level process enters state $j$ equals the rate at which the inventory level process leaves state $j$.

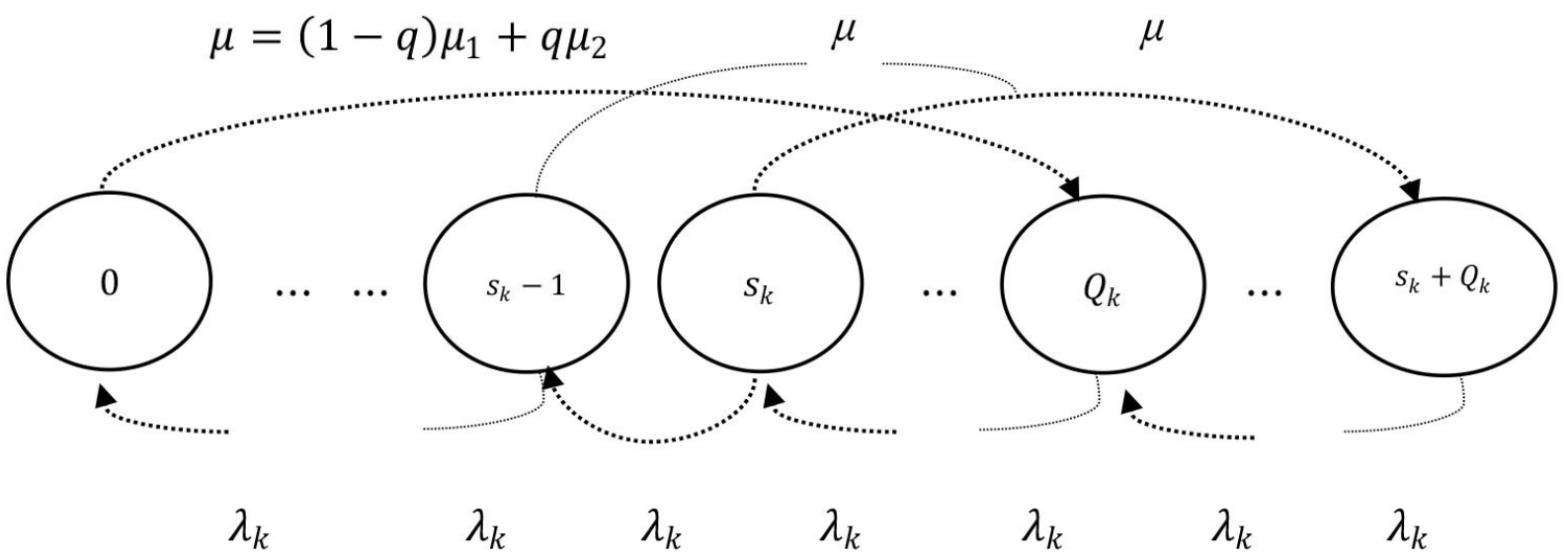

Figure 3. The rate transition diagram for on-hand inventory

From the definition of the birth-death process or a continuous time Markov chain, the balance equations for the steady-state condition are derived as follows. Figure 3 illustrates the rate transition diagram for on-hand inventory for the warehouse located at site $k$. 


$$
\begin{gathered}
\mu P_{k}(j)=\lambda_{k} P_{k}(j+1) \quad j=0 \\
\text { which implies } \mu P_{k}(0)=\lambda_{k} P_{k}(1) . \\
\text { Here } \mu=(1-q) \mu_{1}+q \mu_{2} \\
\left(\mu+\lambda_{k}\right) P_{k}(j)=\lambda_{k} P_{k}(j+1) \quad 1 \leq j \leq s_{k}-1 \\
\left(\mu+\lambda_{k}\right) P_{k}(j)=\lambda_{k} P_{k}(j+1) \quad j=s_{k} \\
\text { which implies }\left(\mu+\lambda_{k}\right) P_{k}\left(s_{k}\right)=\lambda_{k} P_{k}\left(s_{k}+1\right) \\
\lambda_{k} P_{k}(j)=\lambda_{k} P_{k}(j+1) \quad s_{k}+1 \leq j \leq Q_{k}-1 \\
\lambda_{k} P_{k}(j)=\lambda_{k} P_{k}(j+1)+\mu P_{k}\left(j-Q_{k}\right) \quad Q_{k} \leq j \leq Q_{k}+s_{k}-1 \\
\lambda_{k} P_{k}(j)=\mu P_{k}\left(j-Q_{k}\right) \quad j=Q_{k}+s_{k} \\
\text { which implies } \lambda_{k} P_{k}\left(Q_{k}+s_{k}\right)=\mu P_{k}\left(s_{k}\right)
\end{gathered}
$$

Now if $1 \leq j \leq s_{k}$, then by solving Equation (2) or (3) recursively, we have

$$
P_{k}(j)=\left(1+\frac{\mu}{\lambda_{k}}\right)^{j-1} P_{k}(1) \quad 1 \leq j \leq s_{k}
$$

Again replacing the value of $P_{k}(1)$ from Equation (1) and by letting $\mu=(1-q) \mu_{1}+q \mu_{2}$ we have

$$
P_{k}(j)=\left\{1+\frac{(1-q) \mu_{1}+q \mu_{2}}{\lambda_{k}}\right\}^{j-1} \frac{(1-q) \mu_{1}+q \mu_{2}}{\lambda_{k}} P_{k}(0) \quad 1 \leq j \leq s_{k}
$$

From Equation (4), if $s_{k}+1 \leq j \leq Q_{k}-1$, then we have $P_{k}\left(s_{k}+1\right)=P_{k}\left(s_{k}+2\right)=\cdots=P_{k}\left(Q_{k}\right)$. After solving Equation (5) recursively for $j=Q_{k}$ and putting the value of $P_{k}\left(Q_{k}+s_{k}\right)$ of Equation (6) to this recursive equation, we finally have $P_{k}\left(Q_{k}\right)=\left\{1+\frac{(1-q) \mu_{1}+q \mu_{2}}{\lambda_{k}}\right\} \frac{s_{k}}{\lambda_{k}} \frac{(1-q) \mu_{1}+q \mu_{2}}{\lambda_{k}} P_{k}(0)$ (see Appendix A). As a result, $P_{k}\left(s_{k}+1\right)=P_{k}\left(s_{k}+2\right)=\cdots=P_{k}\left(Q_{k}\right)=\left(1+\frac{\mu}{\lambda_{k}}\right)^{s_{k}} \frac{\mu}{\lambda_{k}} P_{k}(0)$. Finally, we have the following equation.

$$
P_{k}(j)=\left\{1+\frac{(1-q) \mu_{1}+q \mu_{2}}{\lambda_{k}}\right\} \frac{s_{k}}{\frac{(1-q) \mu_{1}+q \mu_{2}}{\lambda_{k}}} P_{k}(0) \quad s_{k}+1 \leq j \leq Q_{k}
$$

Again after solving Equations (5) recursively for $j=Q_{k}, Q_{k}+1, Q_{k}+2, \cdots, Q_{k}+s_{k}-1$ and by putting the value of

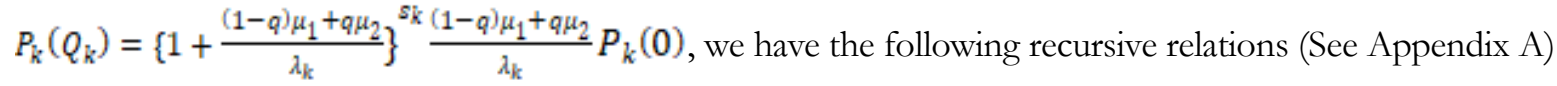

$$
P_{k}\left(Q_{k}+1\right)=\left[\left\{1+\frac{(1-q) \mu_{1}+q \mu_{2}}{\lambda_{k}}\right\}^{s k}-1\right] \frac{(1-q) \mu_{1}+q \mu_{2}}{\lambda_{k}} P_{k}(0)
$$




$$
\begin{gathered}
P_{k}\left(Q_{k}+2\right)=\left[\left\{1+\frac{(1-q) \mu_{1}+q \mu_{2}}{\lambda_{k}}\right\}^{s_{k}}-\left\{1+\frac{(1-q) \mu_{1}+q \mu_{2}}{\lambda_{k}}\right\}\right] \frac{(1-q) \mu_{1}+q \mu_{2}}{\lambda_{k}} P_{k}(0), \\
\vdots \\
\vdots \\
P_{k}\left(Q_{k}+s_{k}\right)=\left[\left\{1+\frac{(1-q) \mu_{1}+q \mu_{2}}{\lambda_{k}}\right\}^{s_{k}}-\left\{1+\frac{(1-q) \mu_{1}+q \mu_{2}}{\lambda_{k}}\right\}^{s_{k}-1}\right] \frac{(1-q) \mu_{1}+q \mu_{2}}{\lambda_{k}} P_{k}(0) .
\end{gathered}
$$

From the above recursive relations, the final expression of $P_{k}(j)$ can be expressed as follows

$$
\begin{gathered}
P_{k}(j)=\left[\left\{1+\frac{(1-q) \mu_{1}+q \mu_{2}}{\lambda_{k}}\right\}_{k}^{s_{k}}-\left\{1+\frac{(1-q) \mu_{1}+q \mu_{2}}{\lambda_{k}}\right\}^{j-Q_{k}-1}\right] \frac{(1-q) \mu_{1}+q \mu_{2}}{\lambda_{k}} P_{k}(0) \\
Q_{k}+1 \leq j \leq Q_{k}+s_{k} .
\end{gathered}
$$

Since $\sum_{j=0}^{Q_{k}+s_{k}} P_{k}(j)=1$ from Equations (8) to (10), we have the following equation (See Appendix A for details).

$$
P_{k}(0)=\frac{\lambda_{k}}{\lambda_{k}+Q_{k}\left\{(1-q) \mu_{1}+q \mu_{2}\right\}\left\{1+\frac{(1-q) \mu_{1}+q \mu_{2}}{\lambda_{k}}\right\}^{s_{k}}}
$$

Using the queuing approach, the mean re-order rate in each opened warehouse can be derived. According to PASTA (Poisson arrivals see time averages) property, the probability of having an on-hand inventory level $s_{k}+1$ in the long run, i.e., $P_{k}\left(s_{k}+1\right)$ equals the proportion of demand arrivals that finds an inventory level of $s_{k}+1$ while arrives.

The average number of demand arrivals per unit time is $\lambda_{k}$, and hence, the average number of demand arrivals that finds an inventory level of $s_{k}+1$ per unit time is $P_{k}\left(s_{k}+1\right) \lambda_{k}$. The number $P_{k}\left(s_{k}+1\right) \lambda_{k}$ also denotes the average number of demand arrivals that left behind an inventory level of $s_{k}$ per unit time while departs. As a result, the mean number of times a warehouse has state $s_{k}$ or the mean number of times a warehouse manager finds an on-hand inventory position of $s_{k}$ is $P_{k}\left(s_{k}+1\right) \lambda_{k}$. From this, the mean re-order rate in each opened warehouse $k$ can be derived by the following equation.

$$
O_{k}=P_{k}\left(s_{k}+1\right) \lambda_{k}=\left\{1+\frac{(1-q) \mu_{1}+q \mu_{2}}{\lambda_{k}}\right\}^{s_{k}}\left\{(1-q) \mu_{1}+q \mu_{2}\right\} P_{k}(0)
$$

Again using the queuing approach, the average inventory level in each opened warehouse $k$ can be derived by the following equation (see Appendix A for details).

$$
\begin{gathered}
L_{k}=\sum_{j \in E_{k}} j P_{k}(j)=\left(1+\frac{\mu}{\lambda_{k}}\right)^{s_{k}} P_{k}(0)\left\{\frac{\mu}{2 \lambda_{k}}\left(Q_{k}{ }^{2}+Q_{k}+2 Q_{k} s_{k}\right)-Q_{k}\right\}+P_{k}(0) Q_{k} \\
\text { Here } \mu=(1-q) \mu_{1}+q \mu_{2}
\end{gathered}
$$

Like the mean re-order rate, the mean lost sales rate in each opened warehouse $k$ can be derived by the following equation. 


$$
B_{k}=P_{k}(0) \lambda_{k}=\frac{\lambda_{k}{ }^{2}}{\lambda_{k}+Q_{k}\left\{(1-q) \mu_{1}+q \mu_{2}\right\}\left\{1+\frac{(1-q) \mu_{1}+q \mu_{2}}{\lambda_{k}} s_{k}\right.}
$$

\subsection{Manufacturer's Production, Shipment, and Emission Level Formulation}

Since each opened warehouse $k$ places an order of $Q_{k}$ to the manufacturing plant when the inventory level declines to $s_{k}$. So the mean production rate of the manufacturing plant for warehouse $k$ is derived by the following equation.

$$
Y_{k}=Q_{k} O_{k}=Q_{k}\left\{1+\frac{(1-q) \mu_{1}+q \mu_{2}}{\lambda_{k}}\right\}^{s_{k}}\left\{(1-q) \mu_{1}+q \mu_{2}\right\} P_{k}(0)
$$

The expected transportation quantity per unit time from the manufacturing plant to the opened warehouse $k$ is $Y_{k}$. On the other hand, the expected transportation quantity per unit time from the warehouse $k$ to the assigned demand centers $i$ can now be derived by the following equation.

$$
\begin{gathered}
G_{k}=\left\{1-P_{k}(0)\right\} \lambda_{k} \\
\text { Here } \lambda_{k}=\sum_{i \in I} \lambda^{i} V_{k i}
\end{gathered}
$$

The manufacturer produces a significant level of emission from production, transportation, and warehousing of the spare parts. The amount of $\mathrm{CO}_{2}$ emitted by shipping one unit (lot) of spare parts from the designated plant to the warehouse $k$ is denoted as $\varphi_{1 k}$ (Nouira, Hammami, Frein \& Temponi, 2016). Similarly, the amount of $\mathrm{CO}_{2}$ emitted by shipping one unit of spare parts from the alternative plant to the warehouse $k$ is denoted as $\varphi_{2 k}$. Again the amount of $\mathrm{CO}_{2}$ emitted by shipping one unit (lot) of spare parts from the warehouse $k$ to the demand center $i$ is denoted as $\varphi_{k i}$. On the other hand, the amount of $\mathrm{CO}_{2}$ emitted by holding one unit (lot) of inventory in warehouse $k$ is denoted as $\delta_{k}$ (Tang, Ji \& Jiang, 2016). The emission also generates from the production of spare parts. $\partial_{1}$ and $\partial_{2}$ denote the emission index and are defined as the amount of $\mathrm{CO}_{2}$ produced by the production of a single unit (lot) of spare parts (Ben-Salem, Gharbi \& Hajji, 2015; Chen and Monahan, 2010) from the designated and the alternative manufacturing plant, respectively. The maximum limit of emission per unit time set by the environmental emission regulation policy is $\varnothing^{\max }$. If the manufacturer exceeds this limit while managing its supply chain operation, then the manufacturer incurs a cost known as emission cost. The average emission level per unit time of the manufacturer for warehouse $k$ can now be derived as follows.

$$
\begin{gathered}
\omega_{k}=\overbrace{\underbrace{\left\{\varphi_{1 k}(1-q)+q \varphi_{2 k}\right\} Y_{k}}_{\text {Expected value }}+\left\{1-P_{k}(0)\right\} \sum_{i \in I} \varphi_{k i} \lambda^{i} V_{k i}}^{\text {Production }}+\overbrace{L_{k} \delta_{k}}^{\text {Transportation }} \\
+\overbrace{\text { Expected value }}^{\overbrace{\left.\partial_{1}(1-q)+q \partial_{2}\right\} Y_{k}}}
\end{gathered}
$$

\subsection{Supply Chain Cost Functions}

The manufacturer's overall supply chain costs can be broken down into two parts. The fixed setup cost of the warehouse, and the other variable cost. The variable cost includes the spare part's average manufacturing cost per unit time, the average transportation cost per unit time, the long-run average inventory holding cost, the average lost sales cost per unit time, and the average emission cost per unit time. The total supply chain cost can be defined as follows. 


$$
\begin{aligned}
C^{T}=\underbrace{\sum_{k \in K} \Omega U_{k}}_{\text {Setup cost }} & +\underbrace{\max \left(\sum_{k \in K} \omega_{k} U_{k}-\emptyset^{\max }, 0\right) y_{0}}_{\text {Manufacturing cost }}+\underbrace{\sum_{k \in K} Y_{k} y_{1} U_{k}}_{\text {Lost sales cost }}+\underbrace{\sum_{k \in K} B_{k} y_{2} U_{k}}_{\text {Transportation cost }} \\
& +\underbrace{\sum_{k \in K}\left[\left\{y_{1 k}(1-q)+q y_{2 k}\right\} Y_{k}+G_{k} y_{k i}\right] U_{k}}_{\text {Inventory holding cost }}+\underbrace{L_{\text {hest }}}_{\sum_{k} L_{k} y_{3} U_{k}} \\
& \text { Here } G_{k} y_{k i}=\left\{1-P_{k}(0)\right\} \lambda_{k} y_{k i}=\left\{1-P_{k}(0)\right\} \sum_{i \in I} \lambda^{i} V_{k i} y_{k i}
\end{aligned}
$$

\subsection{Integrated Optimization Model}

The proposed optimization model can now be derived by the following expressions.

Minimize Cost: $C^{T}$

Subject to

$$
\begin{gathered}
\sum_{k \in K} V_{k i}=1 \quad \forall i \in I, \\
V_{k i} \leq U_{k} \quad \forall i \in I, \quad \forall k \in K, \\
\lambda_{k}=\sum_{i \in I} \lambda^{i} V_{k i} \quad \forall k \in K, \\
s_{k}<Q_{k} \quad \forall k \in K, \\
Q_{k}+s_{k} \leq I^{k}{ }_{\max } \quad \forall k \in K, \\
V_{k i} \in\{0,1\} \quad \forall i \in I, \forall k \in K, \\
U_{k} \in\{0,1\} \quad \forall k \in K, \\
Q_{k} \geq 0 \quad Q_{k}, s_{k} \text { Integer } \forall k \in K .
\end{gathered}
$$

The Objective function (19) minimizes the total supply chain cost. The Equality constraint (20) ensures that each demand center is assigned to exactly one warehouse located at location $k$. The Constraint (21) ensures that a demand center can only be assigned to an opened warehouse located at location $k$. The Constraint (22) guarantees that the demand rate allocated to each opened warehouse $k$ is equal to the sum of demand rates of its assigned demand centers $i$. The Constraint (23) confirms that the re-order point is always less than the reorder quantity at each opened warehouse to avoid any perpetual shortages. The Constraint (24) confirms that the summation of the reorder level and the reorder quantity for warehouse $k$ never exceeds the maximum inventory capacity of this warehouse. Constraint (25) and (26) define the domain of the decision variables $V_{k i}$ and $U_{k}$, respectively. 


\subsection{Solution Approach}

The optimization problem is a mixed-integer programming problem, and therefore, it is solved using the Genetic algorithm solver of the global optimization toolbox of MATLAB. Since the Genetic algorithm is a heuristic search algorithm, and thus it always gives a near-optimal solution.

\section{Numerical Experiment and Sensitivity Analysis}

\subsection{Numerical Examples}

The following numerical values (Table 3) of the input parameters are assumed for conducting a numerical experiment for the derived model. We assumed that the maximum inventory level for all possible warehouses $k \in\{1,2 \ldots K\}$ is 9 lots, and each lot contains 100 units of spare parts.

\begin{tabular}{|c|r|c|r|}
\hline$q$ & 0.10 & $\delta_{k=1}$ & 0.045 \\
\hline$\mu_{1}$ & 1.03 & $\delta_{k=2}$ & 0.045 \\
\hline$\mu_{2}$ & 0.73 & $\Omega$ & $\$ 5$ \\
\hline$\varnothing^{\text {max }}$ & 4 & $y_{0}$ & $\$ 8$ \\
\hline$\partial_{1}$ & 0.077 & $y_{1}$ & $\$ 10$ \\
\hline$\partial_{2}$ & 0.077 & $y_{2}$ & $\$ 36$ \\
\hline$I_{\text {max }}^{k}$ & 9 & $y_{3}$ & $\$ 2$ \\
\hline
\end{tabular}

Table 3. Common input parameters

Based on Table 4, three numerical experiments are performed, which are described as follows.

\begin{tabular}{|c|c|c|c|c|}
\hline \multirow{13}{*}{$\begin{array}{l}\text { Example } 1 \text {. } \\
3 \text { demand center, } \\
2 \text { possible location } \\
\text { of warehouse }\end{array}$} & K & $\kappa \in\{1,2, \ldots K\}$ & $\varphi_{k=2 i=2}$ & 0.25 \\
\hline & $I$ & $\imath \in\{1,2,3 \ldots I\}$ & $\varphi_{k=2 i=3}$ & 0.20 \\
\hline & $\lambda^{1}$ & 1.5 & $y_{1 k=1}$ & $\$ 2.10$ \\
\hline & $\lambda^{2}$ & 1.7 & $y_{1 k=2}$ & $\$ 2.50$ \\
\hline & $\lambda^{3}$ & 1.2 & $y_{2 k=1}$ & $\$ 2.75$ \\
\hline & $\varphi_{1 k=1}$ & 1.1 & $y_{2 k=2}$ & $\$ 2.80$ \\
\hline & $\varphi_{1 k=2}$ & 1.3 & $y_{k=1 i=1}$ & $\$ 0.12$ \\
\hline & $\varphi_{2 k=1}$ & 1.4 & $y_{k=1 i=2}$ & $\$ 0.32$ \\
\hline & $\varphi_{2 k=2}$ & 1.5 & $y_{k=1 i=3}$ & $\$ 0.50$ \\
\hline & $\varphi_{k=1 i=1}$ & 0.15 & $y_{k=2 i=1}$ & $\$ 0.60$ \\
\hline & $\varphi_{k=1 i=2}$ & 0.19 & $y_{k=2 i=2}$ & $\$ 0.58$ \\
\hline & $\varphi_{k=1 i=3}$ & 0.23 & $y_{k=2 i=3}$ & $\$ 0.33$ \\
\hline & $\varphi_{k=2 i=1}$ & 0.29 & & \\
\hline \multirow{3}{*}{$\begin{array}{l}\text { Example } 2 . \\
4 \text { demand center, } \\
2 \text { possible location } \\
\text { of warehouse }\end{array}$} & $\varphi_{k=1 i=4}$ & 0.25 & $y_{k=1 i=4}$ & $\$ 0.58$ \\
\hline & $\varphi_{k=2 i=4}$ & 0.31 & $y_{k=2 i=4}$ & $\$ 0.62$ \\
\hline & \multicolumn{4}{|c|}{$\lambda^{4}=2$} \\
\hline \multirow{3}{*}{$\begin{array}{l}\text { Example } 3 \text {. } \\
5 \text { demand center, } \\
2 \text { possible location } \\
\text { of warehouse }\end{array}$} & $\varphi_{k=1 i=5}$ & 0.29 & $y_{k=1 i=5}$ & $\$ 0.60$ \\
\hline & $\varphi_{k=2 i=5}$ & 0.23 & $y_{k=2 i=5}$ & $\$ 0.50$ \\
\hline & \multicolumn{4}{|c|}{$\lambda^{5}=2.1$} \\
\hline
\end{tabular}

Table 4. Examples: demand centers and possible location of warehouse 
First, using the data of Table 3 and Table 4, the optimization problem is solved. The findings are shown in Table 5. First, in example 1, the near-optimal solution is obtained by considering both warehouse $1(k=1)$ and warehouse 2 $(k=2)$. Second, the near-optimal solution is obtained by considering only warehouse $1(k=1)$. Finally, the near-optimal solution is obtained by considering only warehouse $2(k=2)$. By considering the total average cost functions, the obtained near-optimal solutions are then evaluated to obtain the ultimate near-optimal solution (see Table 5). The same approach is implemented, for example 2 and example 3 as well. When only a single warehouse $k$ is evaluated for an optimal solution, the optimal values of the decision variables $V_{k i}, U_{k}$, and $\lambda_{k}$ are known by default in advance, and thus we only need to obtain the near-optimal solutions of $Q_{k}$ and $s_{k}$. So for a single warehouse evaluation, the optimization problem turns into a two variables problem.

Based on Table 5, the optimal location of a warehouse for example 1, and example 2 are the same, and it is only the warehouse 1, i.e., the warehouse located in location $k=1$. Figure 4 shows the total average cost function regarding example 1 for various $Q_{1}$, and $s_{1}$. In example 3, the optimal number of warehouses is 2 , i.e., both warehouse 1 and 2, i.e., $k=1$ and 2 . Regarding the three examples mentioned above, the following findings are observed.

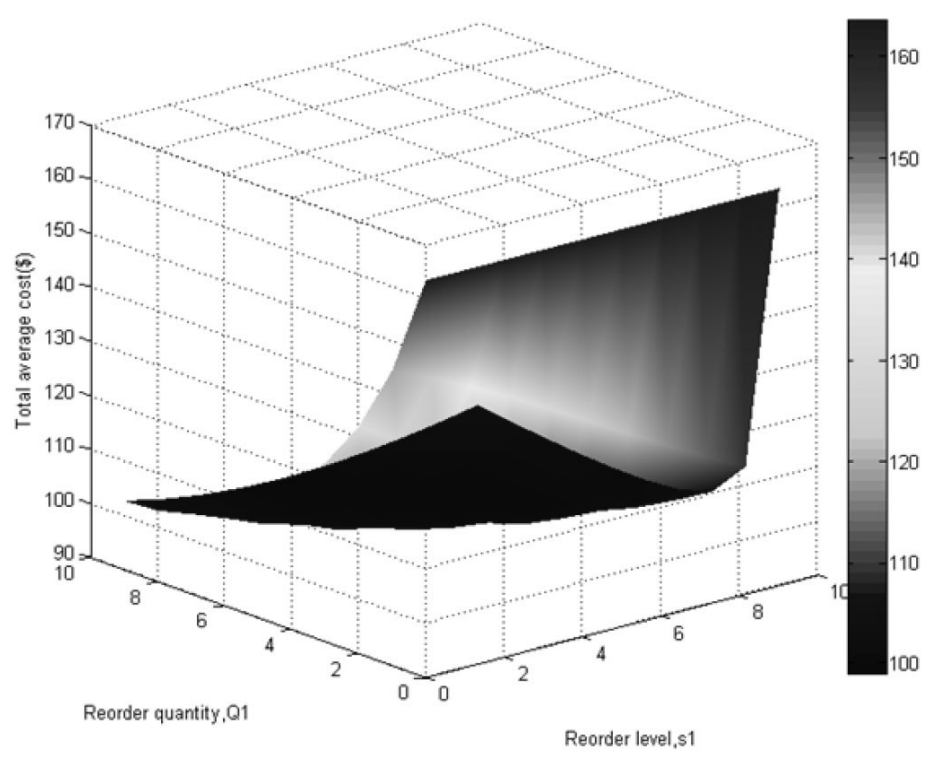

Figure 4. Total average cost function for warehouse 1(Example 1)

\section{Example 1}

For a single warehouse scenario, based on the designed parameters, the obtained $Q_{2}^{*}$ is 5 lots and $s_{2}^{*}$ is 4 lots, for a warehouse located in location 2 . Similarly, the obtained $Q^{*}$ is 5 lots and $s_{1}^{*}$ is 4 lots, for a warehouse located in 1 . As a result, the average lost sales cost is the same for the warehouse located in both locations 1 and location 2 . The same results can be observed for the average inventory holding and the average manufacturing cost. On the other hand, in the case of a warehouse located in location 2 , the unit transportation cost and the per-unit emission level are higher than a warehouse located in location 1. That's why the average transportation cost and the average emission cost for warehouse $2(k=2)$ are higher than the warehouse $1(k=1)$, to minimize the total average cost.

\section{Example 2}

For a single warehouse scenario, based on the designed parameters, the obtained $Q_{2}^{*}$ is 6 lots and $s_{2}^{*}$ is 3 lots, for a warehouse located in location 2 . Similarly, the obtained $Q^{*}$ is 6 lots and $s_{1}^{*}$ is 3 lots, for a warehouse located in 1 . As a result, like Example 1, the average lost sales cost, the average inventory holding, and the average manufacturing cost is the same for both warehouses located in location 2 and location 1, and it is expected. Similarly, like Example 1 , the unit transportation cost for a warehouse located in location 2 is higher than the warehouse located in location 
1.That's why the average transportation cost for warehouse $2(k=2)$ is higher than the warehouse $1(k=1)$. Again the per unit emission level for warehouse $2(k=2)$ is higher than the warehouse $1(k=1)$. That's why the average emission cost for a warehouse located in location 2 is higher than the warehouse located in location 1 to minimize the total average cost.

\section{Example 3}

For a two-warehouse scenario, based on the designed parameters, the obtained $Q_{2}^{*}$ is 5 lots and $s_{2}^{*}$ is 3 lots, for a warehouse located in location 2 . The obtained $Q^{*}{ }_{1}$ is 6 lots and $s_{1}^{*}$ is 3 lots, for a warehouse located in 1 . In the end, for a two warehouse scenario, although the average lost sales cost is lower than any single warehouse scenario (either $k=1$ or 2 ), the average inventory holding cost, the average manufacturing cost, the average emission cost, the average transportation cost, and the warehouse setup cost are higher than any single warehouse scenario. Finally, for a two-warehouse scenario, the total average cost is the ultimate near-optimal. That is, when the demand center number is 5 , it is better to select both warehouse 1 and warehouse 2 .

\begin{tabular}{|c|c|c|c|c|c|}
\hline \multirow{11}{*}{$\begin{array}{l}\text { Example 1: } \\
3 \text { demand center, } \\
2 \text { possible location } \\
\text { of warehouse }\end{array}$} & $V_{k i}^{*}$ & $\begin{array}{l}V^{*}{ }_{11}=1, V_{12}^{*}=1, \\
V_{13}^{*}=0, V_{21}^{*}=0, \\
V_{22}^{*}=0, V_{23}^{*}=1\end{array}$ & $\begin{array}{l}V_{11}^{*}=1, V_{12}^{*}=1, \\
V_{13}^{*}=1, V_{21}^{*}=0 \\
V_{22}^{*}=0, V^{*}{ }_{23}=0\end{array}$ & $\begin{array}{l}V_{11}^{*}=0, V^{*}{ }_{12}=0 \\
V_{13}^{*}=0, V_{21}^{*}=1 \\
V^{*}{ }_{22}=1, V^{*}{ }_{23}=1\end{array}$ & $\begin{aligned} V^{*}{ }_{11} & =1, V^{*}{ }_{12}=1, \\
V_{13}^{*} & =1, V^{*}{ }_{21}=0, \\
V_{22}^{*} & =0, V_{23}^{*}=0, \\
U_{1}^{*} & =1, U_{2}^{*}=0\end{aligned}$ \\
\hline & $\lambda_{k}^{*}$ & $\begin{array}{l}\lambda_{1}^{*}=3.2 \\
\lambda_{2}^{*}=1.2\end{array}$ & $\begin{array}{c}\lambda_{1}^{*}=4.4 \\
\lambda_{2}^{*}=0\end{array}$ & $\begin{array}{c}\lambda_{1}^{*}=0 \\
\lambda_{2}^{*}=4.4\end{array}$ & $\begin{array}{c}\lambda_{1}^{*}=4.4 \\
\lambda_{2}^{*}=0\end{array}$ \\
\hline & $s_{k}^{*}$ & $\begin{array}{l}s_{1}^{*}=4 \\
s_{2}^{*}=1\end{array}$ & $\begin{array}{l}s_{1}^{*}=4 \\
s_{2}^{*}=0\end{array}$ & $\begin{array}{l}s_{1}^{*}=0 \\
s_{2}^{*}=4\end{array}$ & $\begin{array}{l}s_{1}^{*}=4 \\
s_{2}^{*}=0\end{array}$ \\
\hline & $Q_{k}^{*}$ & $\begin{array}{l}Q_{1}^{*}=5 \\
Q_{2}^{*}=2\end{array}$ & $\begin{array}{l}Q_{1}^{*}=5 \\
Q_{2}^{*}=0\end{array}$ & $\begin{array}{l}Q_{1}^{*}=0 \\
Q_{2}^{*}=5\end{array}$ & $\begin{array}{l}Q_{1}^{*}=5 \\
Q_{2}^{*}=0\end{array}$ \\
\hline & $C^{T^{*}}$ & 106.85 & 99.87 & 108.13 & 99.87 \\
\hline & Transportation cost & 8.88 & 7.82 & 9.67 & 1 warehouse $(k=1)$ \\
\hline & Manufacturing cost & 35.36 & 31.70 & 31.70 & \multirow{6}{*}{$\begin{array}{l}\text { Ultimate near } \\
\text { optimal solution }\end{array}$} \\
\hline & Inventory holding cost & 10.97 & 6.54 & 6.54 & \\
\hline & Lost sales cost & 31.09 & 44.27 & 44.27 & \\
\hline & Emission cost & 10.55 & 4.54 & 10.95 & \\
\hline & Setup cost & 10 & 5 & 5 & \\
\hline \multicolumn{2}{|l|}{ Decision variables } & 2 warehouse $(k=1,2)$ & 1 warehouse $(k=1)$ & 1 warehouse $(k=2)$ & \\
\hline \multirow{11}{*}{$\begin{array}{l}\text { Example } 2 \text { : } \\
4 \text { demand center, } \\
2 \text { possible location } \\
\text { of warehouse }\end{array}$} & $V_{k i}^{*}$ & $\begin{array}{l}V^{*}{ }_{11}=1, V^{*}{ }_{12}=1, \\
V_{13}^{*}=0, V_{14}^{*}=1, \\
V^{*}{ }^{*}=0, V^{*}{ }_{22}=0, \\
V^{*}{ }_{23}=1, V^{*}{ }_{24}=0\end{array}$ & $\begin{array}{l}V^{*}{ }_{11}=1, V^{*}{ }_{12}=1, \\
V^{*}=1, V^{*}{ }_{14}=1, \\
V^{*}{ }_{21}=0, V^{*}{ }_{22}=0, \\
V^{*}{ }_{23}=0, V^{*}{ }_{24}=0\end{array}$ & $\begin{array}{l}V^{*}{ }_{11}=0, V^{*}{ }_{12}=0 \\
V^{*}{ }_{13}=0, V^{*}{ }_{14}=0 \\
V^{*}{ }_{21}=1, V^{*}=1, \\
V^{*}{ }_{23}=1, V^{*}{ }_{24}=1\end{array}$ & $\begin{aligned} U_{1}^{*} & =1, U^{*}{ }_{2}=0, \\
V^{*} & =1, V^{*}{ }_{12}=1, \\
V^{*}{ }_{13} & =1, V^{*}{ }_{14}=1, \\
V^{*}{ }_{21} & =0, V^{*}{ }_{22}=0, \\
V^{*}{ }_{23} & =0, V^{*}{ }_{24}=0\end{aligned}$ \\
\hline & $\lambda_{k}^{*}$ & $\begin{array}{l}\lambda_{1}^{*}=5.2 \\
\lambda_{2}^{*}=1.2\end{array}$ & $\begin{array}{c}\lambda_{1}^{*}=6.4 \\
\lambda_{2}^{*}=0\end{array}$ & $\begin{array}{c}\lambda_{1}^{*}=0 \\
\lambda_{2}^{*}=6.4\end{array}$ & $\begin{array}{c}\lambda_{1}^{*}=6.4 \\
\lambda_{2}^{*}=0\end{array}$ \\
\hline & $s_{k}^{*}$ & $\begin{array}{l}s_{1}^{*}=3 \\
s_{2}^{*}=1\end{array}$ & $\begin{array}{l}s_{1}^{*}=3 \\
s_{2}^{*}=0\end{array}$ & $\begin{array}{l}s_{1}^{*}=0 \\
s_{2}^{*}=3\end{array}$ & $\begin{array}{l}s_{1}^{*}=3 \\
s_{2}^{*}=0\end{array}$ \\
\hline & $Q_{k}^{*}$ & $\begin{array}{l}Q_{1}^{*}=6 \\
Q_{2}^{*}=2\end{array}$ & $\begin{array}{l}Q_{1}^{*}=6 \\
Q_{2}^{*}=0\end{array}$ & $\begin{array}{l}Q_{1}^{*}=0 \\
Q_{2}^{*}=6\end{array}$ & $\begin{array}{l}Q_{1}^{*}=6 \\
Q_{2}^{*}=0\end{array}$ \\
\hline & $C^{T^{*}}$ & 167.33 & 163.37 & 173 & 163.37 \\
\hline & Transportation cost & 11.28 & 9.67 & 11.67 & 1 warehouse $(k=1)$ \\
\hline & Manufacturing cost & 43.45 & 37.87 & 37.87 & \multirow{6}{*}{$\begin{array}{c}\text { Ultimate near } \\
\text { optimal solution }\end{array}$} \\
\hline & Inventory holding cost & 8.72 & 5.02 & 5.02 & \\
\hline & Lost sales cost & 73.98 & 94.07 & 94.07 & \\
\hline & Emission cost & 19.90 & 11.74 & 19.37 & \\
\hline & Setup cost & 10 & 5 & 5 & \\
\hline \multicolumn{2}{|l|}{ Decision variables } & 2 warehouse $(k=1,2)$ & 1 warehouse $(k=1)$ & 1 warehouse $(k=2)$ & \\
\hline
\end{tabular}




\begin{tabular}{|c|c|c|c|c|c|}
\hline \multirow{11}{*}{$\begin{array}{l}\text { Example } 3 \text { : } \\
5 \text { demand center, } \\
2 \text { possible location } \\
\text { of warehouse }\end{array}$} & $V_{k i}^{*}$ & $\begin{array}{l}V^{*}{ }_{11}=1, V^{*}{ }_{12}=1, \\
V^{*}{ }_{13}=0, V^{*}{ }_{14}=1, \\
V^{*}{ }_{15}=0, V^{*}{ }_{21}=0, \\
V^{*}{ }_{22}=0, V^{*}{ }_{23}=1, \\
V^{*}{ }_{24}=0, V^{*}{ }_{25}=1\end{array}$ & $\begin{array}{l}V^{*}{ }_{11}=1, V^{*}{ }_{12}=1, \\
V_{13}^{*}=1, V^{*}{ }_{14}=1, \\
V_{15}^{*}=1, V^{*}{ }_{21}=0, \\
V^{*}{ }_{22}=0, V_{23}^{*}=0, \\
V^{*}{ }_{24}=0, V^{*}{ }_{25}=0\end{array}$ & $\begin{array}{l}V^{*}{ }_{11}=0, V^{*}{ }_{12}=0 \\
V^{*}{ }_{13}=0, V^{*}{ }_{14}=0 \\
V^{*}{ }_{15}=0, V^{*}{ }_{21}=1, \\
V^{*}{ }_{22}=1, V^{*}{ }_{23}=1, \\
V^{*}{ }_{24}=1, V^{*}{ }_{25}=1\end{array}$ & $\begin{aligned} U^{*} & =1, U^{*}=1, \\
V_{11} & =1, V^{*}{ }_{12}=1, \\
V_{13}^{*} & =0, V^{*}{ }_{14}=1, \\
V_{15}^{*} & =0, V^{*}{ }_{21}=0, \\
V_{22}^{*} & =0, V_{23}^{*}=1, \\
V_{24}^{*} & =0, V^{*}{ }_{25}=1\end{aligned}$ \\
\hline & $\lambda_{k}^{*}$ & $\begin{array}{l}\lambda_{1}^{*}=5.2 \\
\lambda_{2}^{*}=3.3\end{array}$ & $\begin{array}{c}\lambda_{1}^{*}=8.5 \\
\lambda_{2}^{*}=0\end{array}$ & $\begin{array}{c}\lambda_{1}^{*}=0 \\
\lambda_{2}^{*}=8.5\end{array}$ & $\begin{array}{l}\lambda_{1}^{*}=5.2 \\
\lambda_{2}^{*}=3.3\end{array}$ \\
\hline & $s_{k}^{*}$ & $\begin{array}{l}s_{1}^{*}=3 \\
s_{2}^{*}=3\end{array}$ & $\begin{array}{l}s_{1}^{*}=1 \\
s_{2}^{*}=0\end{array}$ & $\begin{array}{l}s_{1}^{*}=0 \\
s_{2}^{*}=1\end{array}$ & $\begin{array}{l}s_{1}^{*}=3 \\
s_{2}^{*}=3\end{array}$ \\
\hline & $Q_{k}^{*}$ & $\begin{array}{l}Q_{1}^{*}=6 \\
Q_{2}^{*}=5\end{array}$ & $\begin{array}{l}Q_{1}^{*}=8 \\
Q_{2}^{*}=0\end{array}$ & $\begin{array}{l}Q_{1}^{*}=0 \\
Q_{2}^{*}=8\end{array}$ & $\begin{array}{l}Q_{1}^{*}=6 \\
Q_{2}^{*}=5\end{array}$ \\
\hline & $C^{T^{*}}$ & 230.76 & 232.63 & 242.37 & 230.76 \\
\hline & Transportation cost & 16.24 & 11.35 & 13.37 & 2 warehouse $(k=1,2)$ \\
\hline & Manufacturing cost & 59.82 & 43.57 & 43.57 & \multirow{6}{*}{$\begin{array}{l}\text { Ultimate near optimal } \\
\text { solution }\end{array}$} \\
\hline & Inventory holding cost & 12.24 & 4.72 & 4.72 & \\
\hline & Lost sales cost & 90.63 & 149.13 & 149.13 & \\
\hline & Emission cost & 41.83 & 18.86 & 26.58 & \\
\hline & Setup cost & 10 & 5 & 5 & \\
\hline \multicolumn{2}{|l|}{ Decision variables } & 2 warehouse $(k=1,2)$ & 1 warehouse $(k=1)$ & 1 warehouse $(k=2)$ & \\
\hline
\end{tabular}

Table 5. Solutions of example 1, 2, and 3: Near optimal solution

\subsection{Sensitivity Analysis with Respect to the Facility Disruption Probability}

Sensitivity analysis is performed by changing the disruption probability from its base value of 0.1. See Table 6 for results. From Table 6, it is evident that both the mean production rate and the mean inventory level are linearly decreasing functions of the disruption probability, and the mean lost sales rate is a linearly increasing function of the disruption probability of $q$.

On the other side, the average emission level is a non-linear function with respect to the disruption probability. From Table 6, it is also evident that for the designed parameters when the disruption probability increases from 0.01 to 0.1 , there is a very small increment in the average emission level, a very small decrement in the mean production rate, and the mean inventory level. Here, the mean production rate, the mean inventory level, and the average emission level are more or less the same. However, when the disruption probability increases further from 0.5 to 0.95 , like the mean production rate and the mean inventory level, the average emission level also declines with the increment of the disruption probability. Moreover, the facility disruption probability has a certain effect on $Q^{*}$ and $s_{1}^{*}$. For example, in example 1, when the disruption probability increases from 0.1 to $0.5, Q_{1}^{*}$ increases from 5 lots to 6 lots, and $s_{1}^{*}$ decreases from 4 lots to 3 lots and after that $Q^{*}{ }_{1}$ and $s_{1}^{*}$ does not change with respect to the increment of the disruption probability. Similarly, in example 2, when the disruption probability increases from 0.1 to $0.5, Q^{*}$ increases from 6 lots to 7 lots, and $s_{1}^{*}$ decreases from 3 lots to 2 lots and after that $Q^{*}$ and $s_{1}^{*}$ does not change with respect to the increment of the disruption probability. This is logical because when the disruption probability increases from 0.1 to $0.5, s_{1}^{*}$ (for both examples 1 and 2 ) decreases. As a result, the frequency of reordering decreases, although the quantity in each reorders increases. The decrease in the number of re-ordering decreases the average transportation and emission cost due to transportation from the alternative manufacturing plant to the assigned warehouses. This decrease in average transportation and emission costs helps to minimize the total average cost. When the disruption probability increases further from 0.5 to 0.7 , and so on, $Q^{*}{ }_{1}$ and $s_{1}^{*}$ do not change because, for example, in example $1, Q^{*}$ equals 6 lots is sufficient to meet the average demand of 4.4 lots. On the other side, if $s_{1}^{*}$ decreases, then this decrease helps to increase the total average cost due to the increase in the average shortage cost. Here the average transportation and emission costs decrease is not so significant in comparison to the average shortage cost increase. In example $3, Q^{*}{ }_{1}+$ $Q_{2}^{*}(=11)$ and $s_{1}^{*}+s_{2}^{*}(=6)$ are large as the average demand rate is 8.5 lots. Furthermore, to minimize the total average cost, $Q_{1}^{*}+Q_{2}^{*}(=11)$ and $s_{1}^{*}+s_{2}^{*}(=6)$ do not change (increase/decrease) further when the probability 
of disruption is high because the average demand rate is always confined to 8.5 lots. However, based on Equation (15) and Equation (17), as $q$ increases (from 0.5 to 0.95 ), that's why the average emission level $\left(w_{1}^{*}+\right.$ $w_{2}^{*}$ ) decreases (9.26 to 9.07$)$.

\begin{tabular}{|c|c|c|c|c|c|c|c|c|}
\hline \multicolumn{9}{|c|}{ Example 1 (3 demand center, 2 possible location of warehouse) } \\
\hline \multirow{2}{*}{ Near optimal solution } & \multicolumn{8}{|c|}{1 warehouse $(k=1)$} \\
\hline & 0.01 & 0.05 & $\begin{array}{c}0.1 \\
\text { (Base value) }\end{array}$ & 0.5 & 0.7 & 0.8 & 0.9 & 0.95 \\
\hline$Y_{1}^{*}(q)$ & 3.21 & 3.19 & 3.17 & 2.97 & 2.87 & 2.81 & 2.75 & 2.72 \\
\hline$L_{1}^{*}(q)$ & 3.33 & 3.30 & 3.27 & 2.96 & 2.83 & 2.76 & 2.69 & 2.65 \\
\hline$B_{1}^{*}(q)$ & 1.19 & 1.21 & 1.23 & 1.43 & 1.53 & 1.59 & 1.65 & 1.68 \\
\hline$w^{*}{ }_{1}\left(q, Y_{1}^{*}, L_{1}^{*}\right)$ & 4.54 & 4.55 & 4.57 & 4.63 & 4.64 & 4.63 & 4.62 & 4.61 \\
\hline$Q_{1}^{*}$ & 5 & 5 & 5 & 6 & 6 & 6 & 6 & 6 \\
\hline$s_{1}^{*}$ & 4 & 4 & 4 & 3 & 3 & 3 & 3 & 3 \\
\hline \multicolumn{9}{|c|}{ Example 2 ( 4 demand center, 2 possible location of warehouse) } \\
\hline Disruption probability $q$ & \multicolumn{8}{|c|}{1 warehouse $(k=1)$} \\
\hline Near optimal solution & 0.01 & 0.05 & $\begin{array}{c}0.1 \\
\text { (Base value) }\end{array}$ & 0.5 & 0.7 & 0.8 & 0.9 & 0.95 \\
\hline$Y^{*}{ }_{1}(q)$ & 3.85 & 3.82 & 3.79 & 3.55 & 3.41 & 3.34 & 3.26 & 3.22 \\
\hline$L_{1}^{*}(q)$ & 2.56 & 2.53 & 2.51 & 2.41 & 2.31 & 2.25 & 2.19 & 2.17 \\
\hline$B_{1}^{*}(q)$ & 2.55 & 2.58 & 2.61 & 2.85 & 2.99 & 3.06 & 3.14 & 3.18 \\
\hline$w^{*}{ }_{1}\left(q, Y^{*}{ }_{1}, L_{1}^{*}\right)$ & 5.45 & 5.46 & 5.47 & 5.55 & 5.54 & 5.52 & 5.50 & 5.48 \\
\hline$Q_{1}^{*}$ & 6 & 6 & 6 & 7 & 7 & 7 & 7 & 7 \\
\hline$s_{1}^{*}$ & 3 & 3 & 3 & 2 & 2 & 2 & 2 & 2 \\
\hline \multicolumn{9}{|c|}{ Example 3 (5 demand center, 2 possible location of warehouse) } \\
\hline Disruption probability $q$ & \multicolumn{8}{|c|}{2 warehouse $(k=1,2)$} \\
\hline Near optimal solution & 0.01 & 0.05 & $\begin{array}{c}0.1 \\
\text { (Base value) }\end{array}$ & 0.5 & 0.7 & 0.8 & 0.9 & 0.95 \\
\hline$Y_{1}^{*}(q)+Y_{2}^{*}(q)$ & 6.06 & 6.03 & 5.98 & 5.63 & 5.43 & 5.33 & 5.21 & 5.15 \\
\hline$L_{1}^{*}(q)+L_{2}^{*}(q)$ & 6.22 & 6.18 & 6.12 & 5.65 & 5.39 & 5.26 & 5.12 & 5.04 \\
\hline$B_{1}^{*}(q)+B_{2}^{*}(q)$ & 2.44 & 2.47 & 2.52 & 2.87 & 3.07 & 3.17 & 3.29 & 3.35 \\
\hline$w_{1}^{*}\left(q, Y_{1}^{*}, L_{1}^{*}\right)+w_{2}^{*}\left(q, Y_{2}^{*}, L_{2}^{*}\right)$ & 9.20 & 9.21 & 9.22 & 9.26 & 9.21 & 9.16 & 9.11 & 9.07 \\
\hline$Q_{1}^{*}$ & 6 & 6 & 6 & 6 & 6 & 6 & 6 & 6 \\
\hline$s_{1}^{*}$ & 3 & 3 & 3 & 3 & 3 & 3 & 3 & 3 \\
\hline$Q_{2}^{*}$ & 5 & 5 & 5 & 5 & 5 & 5 & 5 & 5 \\
\hline$s_{2}^{*}$ & 3 & 3 & 3 & 3 & 3 & 3 & 3 & 3 \\
\hline
\end{tabular}

Table 6. Impact of the facility disruption probability

Finally, from Table 6, we can conclude that when the disruption probability decreases from 0.95 to 0.5 , the mean production rate and the mean inventory level increase, and as a result, the average emission level also increases. However, when the disruption probability decreases further from 0.1 to 0.01 , there are no significant changes in production, inventory level, and emission level. In conclusion, even though the high probability of facility 
disruption has an impact on the average emission level, but the low disruption probability has no influence on the average emission level.

\subsection{Sensitivity Analysis with Respect to the Emission Limits}

Sensitivity analysis is performed by changing the emission limits from its base value of 4 . See Table 7 for results. From Table 7, it is obvious that for the designed parameters, the emission limit has no influence on the mean production rate, the mean inventory level, the mean lost sales rate, the mean emission level, $Q^{*}{ }_{1}$ and $\mathrm{s}_{1}{ }_{1}$. Since the mean production rate and the mean inventory level remain the same and therefore, the expected emission cost per unit time increases with the emission limit decrease. Thus, the emission limit does not influence controlling the average emission level.

\begin{tabular}{|c|c|c|c|c|c|c|c|}
\hline \multicolumn{8}{|c|}{ Example 1 ( 3 demand center, 2 possible location of warehouse) } \\
\hline \multirow[b]{2}{*}{ Near optimal solution } & \multicolumn{7}{|c|}{1 warehouse $(k=1)$} \\
\hline & 1 & 2 & 3 & $\begin{array}{c}4 \\
\text { (Base value) }\end{array}$ & 5 & 6 & 7 \\
\hline Emission $\operatorname{cost}(\$)^{*}$ & 28.54 & 20.54 & 12.54 & 4.54 & 0 & 0 & 0 \\
\hline$Y_{1}^{*}$ & 3.17 & 3.17 & 3.17 & 3.17 & 3.17 & 3.17 & 3.17 \\
\hline$L_{1}^{*}$ & 3.27 & 3.27 & 3.27 & 3.27 & 3.27 & 3.27 & 3.27 \\
\hline$B_{1}^{*}$ & 1.23 & 1.23 & 1.23 & 1.23 & 1.23 & 1.23 & 1.23 \\
\hline$w_{1}^{*}\left(Y_{1}^{*}, L_{1}^{*}\right)$ & 4.57 & 4.57 & 4.57 & 4.57 & 4.57 & 4.57 & 4.57 \\
\hline$Q_{1}^{*}$ & 5 & 5 & 5 & 5 & 5 & 5 & 5 \\
\hline$s_{1}^{*}$ & 4 & 4 & 4 & 4 & 4 & 4 & 4 \\
\hline
\end{tabular}

\begin{tabular}{|c|c|c|c|c|c|c|c|}
\hline \multicolumn{8}{|c|}{ Example 3 (5 demand center, 2 possible location of warehouse) } \\
\hline \multirow[b]{2}{*}{ Near optimal solution } & \multicolumn{7}{|c|}{2 warehouse $(k=1,2)$} \\
\hline & 1 & 2 & 3 & $\begin{array}{c}4 \\
\text { (Base value) }\end{array}$ & 5 & 6 & 7 \\
\hline Emission $\operatorname{cost}(\$)^{*}$ & 65.83 & 57.83 & 49.83 & 41.83 & 33.83 & 25.83 & 17.83 \\
\hline$Y_{1}^{*}+Y_{2}^{*}$ & 5.98 & 5.98 & 5.98 & 5.98 & 5.98 & 5.98 & 5.98 \\
\hline$L_{1}^{*}+L_{2}^{*}$ & 6.12 & 6.12 & 6.12 & 6.12 & 6.12 & 6.12 & 6.12 \\
\hline$B_{1}^{*}+B_{2}^{*}$ & 2.52 & 2.52 & 2.52 & 2.52 & 2.52 & 2.52 & 2.52 \\
\hline$w_{1}^{*}\left(Y_{1}^{*}, L_{1}^{*}\right)+w_{2}^{*}\left(Y_{2}^{*}, L_{2}^{*}\right)$ & 9.22 & 9.22 & 9.22 & 9.22 & 9.22 & 9.22 & 9.22 \\
\hline$Q^{*}{ }_{1}$ & 6 & 6 & 6 & 6 & 6 & 6 & 6 \\
\hline$s_{1}^{*}$ & 3 & 3 & 3 & 3 & 3 & 3 & 3 \\
\hline$Q_{2}^{*}$ & 5 & 5 & 5 & 5 & 5 & 5 & 5 \\
\hline$s_{2}^{*}$ & 3 & 3 & 3 & 3 & 3 & 3 & 3 \\
\hline
\end{tabular}

Table 7. Impact of the emission limit

\subsection{Sensitivity Analysis With Respect to the Unit Lost Sales Cost}

Sensitivity analysis is performed by changing the unit lost sales cost from its base value of 36. See Table 8 for results. From Table 8, it is apparent that for the designed parameters, the mean production rate, mean inventory level, mean lost sales rate and average emission level are influenced by the unit lost sales cost, having values between $\$ 26$ to $\$ 36$ (see example 1) or $\$ 26$ to $\$ 40$ (see example 3). Under this range, the mean production rate, the mean inventory level, and the average emission level are linearly increasing functions of the unit lost sales cost, and the mean lost sales rate is a linearly decreasing function of the unit lost sales cost. The unit lost sales cost also 
influences $Q^{*}{ }_{1}$ and $s_{1}^{*}$. For example, in numerical example $1, s_{1}^{*}$ decreases from 4 to 3 , and from 3 to 2 when the unit lost sales cost decreases from $\$ 36$ to $\$ 30$ and from $\$ 30$ to $\$ 26$, respectively. Again in numerical example $3, Q^{*}$, $Q^{*}, s_{1}^{*}, s_{2}^{*}$ all are changed for the change in the unit lost sales cost.

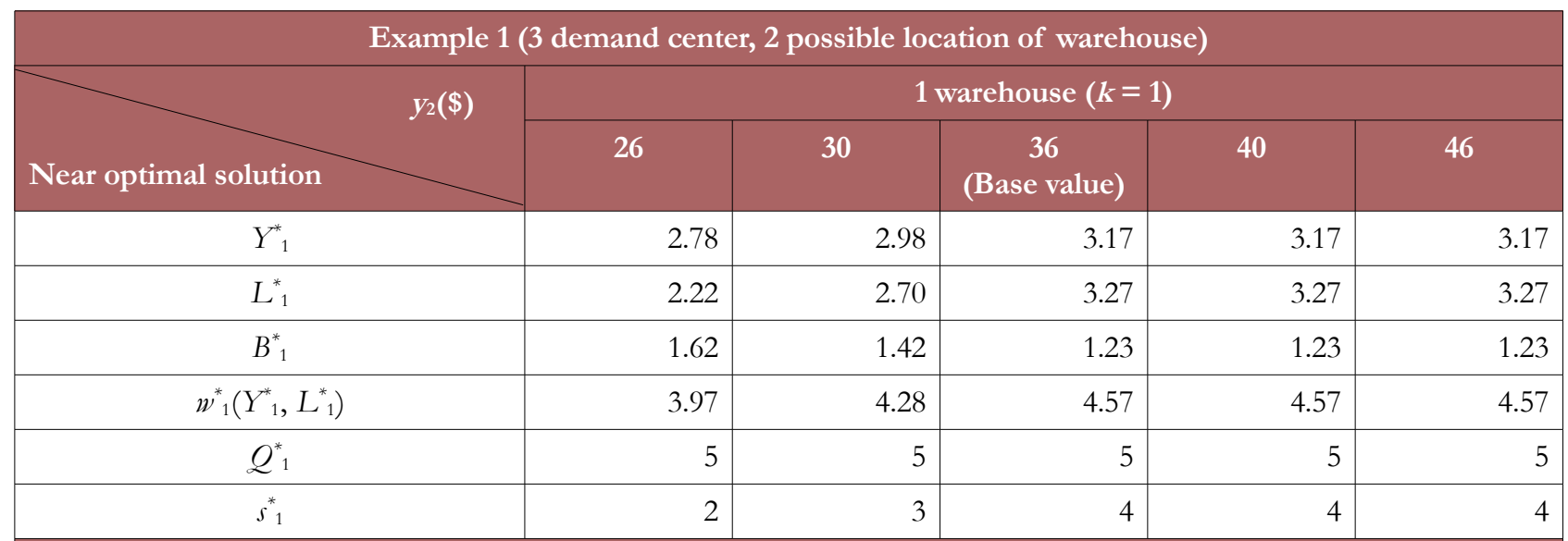

Example 3 (5 demand center, 2 possible location of warehouse)

\begin{tabular}{|c|c|c|c|c|c|}
\hline \multirow[b]{3}{*}{ Near optimal solution } & and cent & ssible lo & ation of warel & & \\
\hline & \multicolumn{5}{|c|}{2 warehouse $(k=1,2)$} \\
\hline & 26 & 30 & $\begin{array}{c}36 \\
\text { (Base value) }\end{array}$ & 40 & 46 \\
\hline$Y_{1}^{*}+Y_{2}^{*}$ & 3.36 & 5.01 & 5.98 & 6.22 & 6.22 \\
\hline$L_{1}^{*}+L_{2}^{*}$ & 1.43 & 3.57 & 6.12 & 6.70 & 6.70 \\
\hline$B_{1}^{*}+B_{2}^{*}$ & 5.14 & 3.49 & 2.52 & 2.28 & 2.28 \\
\hline$w^{*}{ }_{1}^{*}\left(Y_{1}^{*}, L_{1}^{*}\right)+w_{2}^{*}\left(Y_{2}^{*}, L_{2}^{*}\right)$ & 4.96 & 7.51 & 9.22 & 9.81 & 9.81 \\
\hline$Q^{*}{ }_{1}$ & 4 & 6 & 6 & 5 & 5 \\
\hline$s_{1}^{*}$ & 1 & 3 & 3 & 4 & 4 \\
\hline$Q_{2}^{*}$ & 1 & 2 & 5 & 5 & 5 \\
\hline$s_{2}^{*}$ & 0 & 1 & 3 & 4 & 4 \\
\hline
\end{tabular}

Table 8. Impact of the unit lost sales cost

When the unit lost sales cost increases further from $\$ 36$ to $\$ 46$ (example 1 ) or $\$ 40$ to $\$ 46$ (example 3), it does not has any impact on the mean production rate, the mean inventory level, the mean lost sales rate, the average emission levels, $Q^{*}$ and $s^{*}$. It is expected, as the total average demand rate from all the demand centers are 4.4 lots for numerical example 1, or 8.5 lots for numerical example 3. From Table 8 , it is also observed that the unit lost sale cost has little influence on $Q^{*}$ and $s^{*}$ when the average demand rate is low (see example 1 ) but has a significant influence on $Q^{*}$ and $s^{*}$ when the average demand rate is high (see example 3 ).

\subsection{Sensitivity Analysis With Respect to the Unit Emission Cost}

Sensitivity analysis is performed by changing the unit emission cost from its base value of $\$ 8$. See Table 9 for results. From Table 9, it is apparent that for the designed parameters, the mean production rate, mean inventory level, mean lost sales rate and average emission level are influenced by the unit emission cost, having values between $\$ 10$ to $\$ 14$ (see example 1) or $\$ 6$ to $\$ 14$ (see example 3).Under this range, the mean production rate, the mean inventory level, and the average emission level are linearly decreasing functions of the unit emission cost, and the mean lost sales rate is a linearly increasing function of the emission cost. The unit emission cost also influences $s_{1}^{*}$. For example, in numerical example 1, to minimize the total average cost, like the mean production rate, the mean inventory level, and the average emission level, $s_{1}^{*}$ also decreases with the specific range of unit emission cost increments. 
Example 1 (3 demand center, 2 possible location of warehouse)

\section{Unit emission cost $y_{0}$}

\begin{tabular}{|c|r|r|r|r|r|r|}
\hline Near optimal solution & \multicolumn{1}{|c|}{$\begin{array}{c}\text { 4 } \\
\text { (Base value) }\end{array}$} & \multicolumn{1}{|c|}{10} & 12 \\
\hline Total average cost(\$) & 97.60 & 98.74 & 99.87 & 101.00 & 101.97 & 102.48 \\
\hline$Y_{1}^{*}$ & 3.17 & 3.17 & 3.17 & 3.17 & 2.98 & 2.78 \\
\hline$L_{1}^{*}$ & 3.27 & 3.27 & 3.27 & 3.27 & 2.70 & 2.23 \\
\hline$B_{1}^{*}$ & 1.23 & 1.23 & 1.23 & 1.23 & 1.42 & 1.62 \\
\hline$w_{1}^{*}\left(Y_{1}^{*}, L_{1}^{*}\right)$ & 4.57 & 4.57 & 4.57 & 4.57 & 4.28 & 3.97 \\
\hline$Q^{*}{ }_{1}$ & 5 & 5 & 5 & 5 & 5 & 5 \\
\hline$s_{1}^{*}$ & 4 & 4 & 4 & 4 & 3 & 2 \\
\hline
\end{tabular}

Example 3 (5 demand center, 2 possible location of warehouse)

Unit emission cost $y_{o}$

\begin{tabular}{|c|c|c|c|c|c|c|}
\hline Near optimal solution & 4 & 6 & $\begin{array}{c}8 \\
\text { (Base value) }\end{array}$ & 10 & 12 & 14 \\
\hline Total average cost $(\$)$ & 208.07 & 219.69 & 230.76 & 240.70 & 248.16 & 253.31 \\
\hline$Y_{1}^{*}+Y_{2}^{*}$ & 6.22 & 6.22 & 5.98 & 5.66 & 4.81 & 4.18 \\
\hline$L_{1}^{*}+L_{2}^{*}$ & 6.71 & 6.71 & 6.12 & 5.00 & 3.24 & 2.37 \\
\hline$B_{1}^{*}+B_{2}^{*}$ & 2.28 & 2.28 & 2.52 & 2.84 & 3.69 & 4.32 \\
\hline$w_{1}^{*}\left(Y_{1}^{*}, L_{1}^{*}\right)+w_{2}^{*}\left(Y_{2}^{*}, L_{2}^{*}\right)$ & 9.81 & 9.81 & 9.22 & 8.66 & 7.17 & 6.16 \\
\hline$Q^{*}$ & 5 & 5 & 6 & 6 & 6 & 5 \\
\hline$s_{1}^{*}$ & 4 & 4 & 3 & 3 & 3 & 3 \\
\hline$Q_{2}^{*}$ & 5 & 5 & 5 & 4 & 2 & 1 \\
\hline$s_{2}^{*}$ & 4 & 4 & 3 & 2 & 0 & 0 \\
\hline
\end{tabular}

Table 9. Impact of the unit emission cost

Here $s^{*}{ }_{1}$ decreases from 4 lots to 3 lots, and from 3 lots to 2 lots when the unit emission cost increases from $\$ 10$ to $\$ 12$ and $\$ 12$ to $\$ 14$, respectively. For these decrements of $s_{1}^{*}$ the optimal total average supply chain cost becomes $\$ 101.97$ and $\$ 102.48$, respectively. If $s_{1}^{*}$ does not change and remains the same $\left(s_{1}^{*}=4\right)$ for the increment of the unit emission cost to $\$ 12$ and $\$ 14$ from $\$ 10$, then the total average cost would be $\$ 102.14$ and $\$ 103.27$, respectively. On the other hand, $Q^{*}{ }_{1}(=5)$ does not decrease further when the unit emission cost increases because $Q^{*}$ equals 5 lots is sufficient to meet the average demand of 4.4 lots. If $Q^{*}{ }_{1}$ decreases from 5 lots, it eventually increases the total average cost due to the increase in the average shortage cost.

Again in numerical example $3, Q^{*}, Q_{2}^{*}, s_{1}^{*}, s_{2}^{*}$ all are changed for the change in the unit emission cost. From example 3 , it can be observed that when the unit emission cost increases from $\$ 8$ to $\$ 10, Q^{*}{ }_{1}+Q_{2}^{*}$ decreases from 11 lots to 10 lots and $s_{1}^{*}+s_{2}^{*}$ decreases from 6 lots to 5 lots (Table 9). This result indicates that for the unit emission cost increase, the frequency of reordering, and the quantity in each reorders decrease. The decrease in the number of re-ordering and the decrease in the quantity of each reorder, decrease the mean production rate from 5.98 lots to 5.66 lots. Conversely, when the unit emission cost decreases from $\$ 8$ to $\$ 6, Q^{*}{ }_{1}+Q_{2}^{*}$ decreases from 11 lots to 10 lots and $s_{1}^{*}+s_{2}^{*}$ increases from 6 lots to 8 lots (Table 9).This result indicates that for the unit emission cost decrease, the frequency of reordering increases, although the quantity in each reorders decrease. The increase in the number of re-ordering increases the mean production rate from 5.98 lots to 6.22 lots. Moreover, when the unit emission cost decreases from $\$ 6$ to $\$ 4$ (example 3), it does not has any impact on the mean production rate, the mean inventory level, the mean lost sales rate, the average emission levels, $Q_{1}^{*}, Q^{*}{ }_{2}, s_{1}{ }_{1}$ and $s_{2}$. To minimize the total average cost, $Q^{*}+Q_{2}^{*}(=10)$ and $s_{1}^{*}+s_{2}^{*}(=8)$ do not change (increase/decrease) further because the average 
demand rate is always confined to 8.5 lots. Similarly, in example1, when the unit emission cost decreases from $\$ 10$ to $\left.\$ 4, Q^{*}{ }_{1}=5\right)$ and $s_{1}^{*}(=4)$ do not change (increase/decrease) further, as the average demand rate is always confined to 4.4 lots (Table 9).

\section{Conclusions}

We analyzed a supply chain network of spare parts and then optimized the spare part's manufacturer's total average cost. The findings obtained from the numerical analysis (based on the designed parameters) show that if there is a small number of demand centers, then the manufacturer needs to pick a few locations for the warehouse setup. Conversely, when the number of demand centers is large, the large number of warehouses is desirable for the storage and distribution of spare parts. Sensitivity analysis shows that if the number of demand centers is small, and the probability of facility disruption is high, the optimal re-order quantity is large, and the optimal re-order level is low. The opposite results are observed, i.e., the optimal re-order quantity is small, and the optimal re-order level is high, if the number of demand centers is small, and the probability of facility disruption is low. However, when the number of demand centers is large, i.e., the spare part's demand is high; the probability of facility disruption does not influence controlling the warehouse inventory (re-order quantity and the re-order level) system of the spare parts. Also, if the number of demand centers is large, the optimal number of selected warehouses is large, the combined optimal reorder quantity of the selected warehouses is large, and the combined optimal re-order level is also high.

Regarding the environmental sustainability issue, when the probability of facility disruption is significant, it has a positive effect on the environment as the average level of emission decreases (mean production rate decreases) with the increment of the disruption probability. However, the average emission level does not depend on the emission limit. On the other side, although unit lost sales cost has a significant impact on the optimal re-order quantity and the optimal re-order level of the spare parts when the number of demand center is large, but this cost has a very small effect on the optimal re-order quantity and the optimal re-order level when the number of demand center is small.

Nowadays, all industries realize the necessity of a resilient and sustainable supply chain network. A resilient and sustainable supply chain network can only ensure sustainability in the environment, and at the same time, provides economic stability even in the presence of sudden disruption risk. However, the current COVID-19 outbreak clearly shows us that confirming stability in a country's economy is very difficult and more daunting when a natural disaster such as coronavirus spreading occurs because both demand and supply in a supply chain are seriously affected by the assault of this deadly virus although it helps to minimize environmental pollution through the mass lockdown. COVID-19 outbreak also shows that a disaster not only affects an individual organization's supply chain but also affects the whole economy of a country, or in an extreme situation, it affects the whole economy of the world. When someone is planning to develop a green and reliable supply chain network, he or she must consider not only each entity in the network but also all potential other supply chain network variables that are directly / indirectly connected to the network or have an impact on the network. An external variable such as the magnitude of the COVID-19 epidemic, for example, significantly influences the demand and supply rate of the supply chain for a commodity. Now, it is a growing concern whether and how long the supply chain reacts positively to the COVID-19 outbreak so that a product's demand and supply sustain its normal pace throughout this epidemic period. A sustainable and robust supply chain network is desirable. The demanding future research in this regard could be modeling a comprehensive green and robust supply chain network that confirm economic stability while ensuring a less polluted environment. In addition, the limitation of this research is that if the warehouse and demand center number is high, then it takes a long time to solve the problem using the existing solution approach. So to solve the model within a short time, an efficient solution approach can be developed in future.

\section{Declaration of Conflicting Interests}

The authors declared no potential conflicts of interest with respect to the research, authorship, and/or publication of this article.

\section{Funding}

The authors received no financial support for the research, authorship, and/or publication of this article. 


\section{References}

Al Dhaheri, N., \& Diabat, A. (2011). An integrated supply chain problem with environmental considerations. In Seliger, G., Khraisheh, M., \& Jawahir, I. (eds.), Advances in Sustainable Manufacturing (383-388). Berlin, Heidelberg: Springer. https://doi.org/10.1007/978-3-642-20183-7_55

Ahranjani, P.M., Ghaderi, S.F., Azadeh, A., \& Babazadeh, R. (2020). Robust design of a sustainable and resilient bioethanol supply chain under operational and disruption risks. Clean Technologies and Environmental Policy, 22(1), 119-151. https://doi.org/10.1007/s10098-019-01773-2

Arabzad, S.M., Ghorbani, M., \& Tavakkoli-Moghaddam, R. (2015). An evolutionary algorithm for a new multi-objective location-inventory model in a distribution network with transportation modes and third-party logistics providers. International Journal of Production Research, 53(4), 1038-1050. https://doi.org/10.1080/00207543.2014.938836

Azadeh, A., \& Arani, H.V. (2016). Biodiesel supply chain optimization via a hybrid system dynamics-mathematical programming approach. Renewable energy, 93, 383-403. https://doi.org/10.1016/j.renene.2016.02.070

Ben-Salem, A., Gharbi, A., \& Hajji, A. (2015). An Environmental Hedging Point Policy to control production rate and emissions in unreliable manufacturing systems. International Journal of Production Research, 53(2), 435-450. https://doi.org/10.1080/00207543.2014.946161

Berman, O., Krass, D., \& Tajbakhsh, M.M. (2012). A coordinated location-inventory model. European Journal of Operational Research, 217(3), 500-508. https://doi.org/10.1016/j.ejor.2011.09.039

Caglar, D., Li, C.L., \& Simchi-Levi, D. (2004). Two-echelon spare parts inventory system subject to a service constraint. IIE transactions, 36(7), 655-666. https://doi.org/10.1080/07408170490278265

Candas, M.F., \& Kutanoglu, E. (2007). Benefits of considering inventory in service parts logistics network design problems with time-based service constraints. IIE Transactions, 39(2), 159-176.

https://doi.org/10.1080/07408170600729218

Cavalieri, S., Garetti, M., Macchi, M., \& Pinto, R. (2008). A decision-making framework for managing maintenance spare parts. Production planning \& control, 19(4), 379-396. https://doi.org/10.1080/09537280802034471

Chen, C., \& Monahan, G.E. (2010). Environmental safety stock: The impacts of regulatory and voluntary control policies on production planning, inventory control, and environmental performance. European Journal of Operational Research, 207(3), 1280-1292. https://doi.org/10.1016/j.ejor.2010.06.028

Cohen, M.A., Kleindorfer, P.R., \& Lee, H.L. (1989). Near-optimal service constrained stocking policies for spare parts. Operations Research, 37(1), 104-117. https://doi.org/10.1287/opre.37.1.104

Cruz, J.M. (2013). Modeling the relationship of globalized supply chains and corporate social responsibility. Journal of Cleaner Production, 56, 73-85. https://doi.org/10.1016/j.jclepro.2011.09.013

Dai, Z., Aqlan, F., Zheng, X., \& Gao, K. (2018). A location-inventory supply chain network model using two heuristic algorithms for perishable products with fuzzy constraints. Computers \& Industrial Engineering, 119, 338-352. https://doi.org/10.1016/j.cie.2018.04.007

Diabat, A., \& Al-Salem, M. (2015). An integrated supply chain problem with environmental considerations. International Journal of Production Economics, 164, 330-338. https://doi.org/10.1016/j.ijpe.2014.12.004

Diabat, A., Battaïa, O., \& Nazzal, D. (2015). An improved Lagrangian relaxation-based heuristic for a joint location-inventory problem. Computers \& Operations Research, 61, 170-178. https://doi.org/10.1016/j.cor.2014.03.006

Diabat, A., Dehghani, E., \& Jabbarzadeh, A. (2017). Incorporating location and inventory decisions into a supply chain design problem with uncertain demands and lead times. Journal of Manufacturing Systems, 43, 139-149. https://doi.org/10.1016/j.jmsy.2017.02.010

Daskin, M.S., Coullard, C.R., \& Shen, Z.J.M. (2002). An inventory-location model: Formulation, solution algorithm and computational results. Annals of operations research, 110(1-4), 83-106. https://doi.org/10.1023/A:1020763400324 
Driessen, M., Arts, J., van Houtum, G.J., Rustenburg, J.W., \& Huisman, B. (2015). Maintenance spare parts planning and control: a framework for control and agenda for future research. Production Planning \& Control, 26(5), 407-426. https://doi.org/10.1080/09537287.2014.907586

Dehghani, E., \& Taki, P. (2019). Queuing approach and optimal inventory decisions in a stochastic supply chain network design. Journal of Industrial Engineering and Management Studies, 6(2), 165-187.

https://doi.org/10.22116/JIEMS.2019.93498

Farahani, R.Z., Rashidi Bajgan, H., Fahimnia, B., \& Kaviani, M. (2015). Location-inventory problem in supply chains: a modelling review. International Journal of Production Research, 53(12), 3769-3788. https://doi.org/10.1080/00207543.2014.988889

Farahani, M., Shavandi, H., \& Rahmani, D. (2017). A location-inventory model considering a strategy to mitigate disruption risk in supply chain by substitutable products. Computers \& Industrial Engineering, 108, 213-224. https://doi.org/10.1016/j.cie.2017.04.032

Fattahi, M., \& Govindan, K. (2018). A multi-stage stochastic program for the sustainable design of biofuel supply chain networks under biomass supply uncertainty and disruption risk: a real-life case study. Transportation Research Part E: Logistics and Transportation Revien, 118, 534-567. https://doi.org/10.1016/j.tre.2018.08.008

Gold, S., Seuring, S., \& Beske, P. (2010). Sustainable supply chain management and inter-organizational resources: a literature review. Corporate social responsibility and environmental management, 17(4), 230-245. https://doi.org/10.1002/cst.207

Govindan, K., Fattahi, M., \& Keyvanshokooh, E. (2017). Supply chain network design under uncertainty: A comprehensive review and future research directions. European Journal of Operational Research, 263(1), 108-141. https://doi.org/10.1016/j.ejor.2017.04.009

Gunasekaran, A., Patel, C., \& Tirtiroglu, E. (2001). Performance measures and metrics in a supply chain environment. International journal of operations \& production Management, 21, 71- 87. https://doi.org/10.1108/01443570110358468

Hu, Q., Boylan, J.E., Chen, H., \& Labib, A. (2018). OR in spare parts management: A review. European Journal of Operational Research, 266(2), 395-414. https://doi.org/10.1016/j.ejor.2017.07.058

Huiskonen, J. (2001). Maintenance spare parts logistics: Special characteristics and strategic choices. International journal of production economics, 71(1-3), 125-133. https://doi.org/10.1016/S0925-5273(00)00112-2

Ivanov, D., Pavlov, A., Dolgui, A., Pavlov, D., \& Sokolov, B. (2016). Disruption-driven supply chain (re)-planning and performance impact assessment with consideration of pro-active and recovery policies. Transportation Research Part E: Logistics and Transportation Revien, 90, 7-24. https://doi.org/10.1016/j.tre.2015.12.007

Kumar, R.S., Choudhary, A., Babu, S.A.I., Kumar, S.K., Goswami, A., \& Tiwari, M.K. (2017). Designing multi-period supply chain network considering risk and emission: A multi-objective approach. Annals of Operations Research, 250(2), 427-461. https://doi.org/10.1007/s10479-015-2086-z

Kutanoglu, E. (2008). Insights into inventory sharing in service parts logistics systems with time-based service levels. Computers \& Industrial Engineering, 54(3), 341-358. https://doi.org/10.1016/j.cie.2007.07.013

Li, Y., Cheng, Y., Hu, Q., Zhou, S., Ma, L., \& Lim, M.K. (2019). The influence of additive manufacturing on the configuration of make-to-order spare parts supply chain under heterogeneous demand. International Journal of Production Research, 57(11), 3622-3641. https://doi.org/10.1080/00207543.2018.1543975

Li, Y., Guo, H., Wang, L., \& Fu, J. (2013). A hybrid genetic-simulated annealing algorithm for the locationinventory-routing problem considering returns under E-supply chain environment. The Scientific World Journal, 2013. https://doi.org/10.1155/2013/125893

Liu, W., Liu, K., \& Deng, T. (2020). Modelling, analysis and improvement of an integrated chance-constrained model for level of repair analysis and spare parts supply control. International Journal of Production Research, 58(10), 3090-3109. https://doi.org/10.1080/00207543.2019.1629669

Liu, Z., Wang, S., \& Ouyang, Y. (2017). Reliable biomass supply chain design under feedstock seasonality and probabilistic facility disruptions. Energies, 10(11), 1-18. https://doi.org/10.3390/en10111895 
Mak, H.Y., \& Shen, Z.J.M. (2009). A two-echelon inventory-location problem with service considerations. Naval Research Logistics (NRL), 56(8), 730-744. https://doi.org/10.1002/nav.20376

Martin, H., Syntetos, A.A., Parodi, A., Polychronakis, Y.E., \& Pintelon, L. (2010). Integrating the spare parts supply chain: an inter-disciplinary account. Journal of Manufacturing Technology Management, 21(2), 226-245. https://doi.org/10.1108/17410381011014387

Meissner, J., \& Senicheva, O.V. (2018). Approximate dynamic programming for lateral transshipment problems in multi-location inventory systems. European Journal of Operational Research, 265(1), 49-64. https://doi.org/10.1016/j.ejor.2017.06.049

Melo, M.T., Nickel, S., \& Saldanha-Da-Gama, F. (2009). Facility location and supply chain management-A review. European Journal of Operational Research, 196(2), 401-412. https://doi.org/10.1016/j.ejor.2008.05.007

Nouira, I., Hammami, R., Frein, Y., \& Temponi, C. (2016). Design of forward supply chains: Impact of a carbon emissions-sensitive demand. International Journal of Production Economics, 173, 80-98.

https://doi.org/10.1016/j.ijpe.2015.11.002

Peng, Y., Ablanedo-Rosas, J.H., \& Fu, P. (2016). A multiperiod supply chain network design considering carbon emissions. Mathematical Problems in Engineering, 2016. https://doi.org/10.1155/2016/1581893

Rabbani, M., Aliabadi, L., Heidari, R., \& Farrokhi-Asl, H. (2017). Applying queuing theory for a reliable integrated location-inventory problem under facility disruption risks. Journal of Industrial Engineering and Management Studies, 4(2), 1-18. https://doi.org/10.22116/JIEMS.2017.54601

Ramezani, S., \& Naderi, K. (2018). A multi-objective optimization model for locating the distribution warehouses in the logistic network supply chain: A case study of Bonny Chow Co. Journal of Industrial Engineering and Management Studies, 5(1), 26-42. https://doi.org/10.22116/JIEMS.2018.66502

Rayat, F., Musavi, M., \& Bozorgi-Amiri, A. (2017). Bi-objective reliable location-inventory-routing problem with partial backordering under disruption risks: A modified AMOSA approach. Applied Soft Computing, 59, $622-643$. https://doi.org/10.1016/j.asoc.2017.06.036

Sadjadi, S.J., Makui, A., Dehghani, E., \& Pourmohammad, M. (2016). Applying queuing approach for a stochastic location-inventory problem with two different mean inventory considerations. Applied Mathematical Modelling, 40(1), 578-596. https://doi.org/10.1016/j.apm.2015.06.010

Şen, A., Bhatia, D., \& Doğan, K. (2010). Applied materials uses operations research to design its service and parts network. Interfaces, 40(4), 253-266. https:// doi.org/10.1287/inte.1100.0493

Shahabi, M., Unnikrishnan, A., Jafari-Shirazi, E., \& Boyles, S.D. (2014). A three level location-inventory problem with correlated demand. Transportation Research Part B: Methodological, 69, 1-18. https://doi.org/10.1016/j.trb.2014.07.005

Shen, Z.J.M., Coullard, C., \& Daskin, M.S. (2003). A joint location-inventory model. Transportation scienct, $37(1)$, 40-55. https://doi.org/10.1287/trsc.37.1.40.12823

Stevens, G.C. (1989). Integrating the supply chain. International Journal of physical distribution \& Materials Management, 19(8), 3-8. https://doi.org/10.1108/EUM0000000000329

Svendsen, A.C., Boutilier, R.G., Abbott, R.M., \& Wheeler, D. (2001). Measuring the business value of stakeholder relationships (part one). Centre for Innovation in Management, Simon Fraser University, Vancouver, BC, 29-63. Available at: http://citeseerx.ist.psu.edu/viewdoc/download;jsessionid=A3EF06DB0D8DD46151BF14B51A67A863? $\underline{\mathrm{doi}=10.1 .1 .184 .2283 \& \mathrm{rep}=\text { rep1\&type }=\text { pdf }}$ (Accessed: June 2020).

Tang, C.S. (2006). Perspectives in supply chain risk management. International Journal of Production Economics, 103(2), 451-488. https://doi.org/10.1016/j.ijpe.2005.12.006

Tang, J., Ji, S., \& Jiang, L. (2016). The design of a sustainable location-routing-inventory model considering consumer environmental behavior. Sustainability, 8(3), 211. https://doi.org/10.3390/su8030211 
Tapia-Ubeda, F.J., Miranda, P.A., Roda, I., Macchi, M., \& Durán, O. (2020). Modelling and solving spare parts supply chain network design problems. International Journal of Production Research, 1-21.

https://doi.org/10.1080/00207543.2020.1720924

Wagner, S.M., Jönke, R., \& Eisingerich, A.B. (2012). A strategic framework for spare parts logistics. California management revien, 54(4), 69-92. https://doi.org/10.1525/cmr.2012.54.4.69

Wheatley, D.M. (2014). Inventory-Location Problems for Spare Parts with Time-Based Service Constraints. PhD Thesis, University of Waterloo, Canada. http://hdl.handle.net/10012/8185

\section{Appendix A}

Recursive solution of equation (5) for $P_{k}\left(Q_{k}\right)$

From Eq. (5) we have

$$
\begin{gathered}
\lambda_{k} P_{k}(j)=\lambda_{k} P_{k}(j+1)+\mu P_{k}\left(j-Q_{k}\right) \\
\text { which implies } P_{k}(j+1)=P_{k}(j)-\frac{\mu}{\lambda_{k}} P_{k}\left(j-Q_{k}\right) \\
\text { Let } j=Q_{k}, Q_{k}+1, Q_{k}+2, \cdots \cdots Q_{k}+s_{k}-1 \text { which yield } \\
P_{k}\left(Q_{k}+1\right)=P_{k}\left(Q_{k}\right)-\frac{\mu}{\lambda_{k}} P_{k}(0) \\
P_{k}\left(Q_{k}+2\right)=P_{k}\left(Q_{k}\right)-\frac{\mu}{\lambda_{k}} P_{k}(0)-\frac{\mu}{\lambda_{k}} P_{k}(1) \\
P_{k}\left(Q_{k}+3\right)=P_{k}\left(Q_{k}\right)-\frac{\mu}{\lambda_{k}} P_{k}(0)-\frac{\mu}{\lambda_{k}} P_{k}(1)-\frac{\mu}{\lambda_{k}} P_{k}(2) \\
\vdots \\
\vdots \\
P_{k}\left(Q_{k}+s_{k}\right)=P_{k}\left(Q_{k}\right)-\left\{\frac{\mu}{\lambda_{k}} P_{k}(0)+\frac{\mu}{\lambda_{k}} P_{k}(1)+\frac{\mu}{\lambda_{k}} P_{k}(2)+\cdots+\frac{\mu}{\lambda_{k}} P_{k}\left(s_{k}-1\right)\right\}
\end{gathered}
$$

Again from Eq. (6) we have

$$
P_{k}\left(Q_{k}+s_{k}\right)=\frac{\mu}{\lambda_{k}} P_{k}\left(s_{k}\right)
$$

Putting the value of $P_{k}\left(Q_{k}+s_{k}\right)$ in the above recursive equation we have

$$
\begin{gathered}
\frac{\mu}{\lambda_{k}} P_{k}\left(s_{k}\right)=P_{k}\left(Q_{k}\right)-\left\{\frac{\mu}{\lambda_{k}} P_{k}(0)+\frac{\mu}{\lambda_{k}} P_{k}(1)+\frac{\mu}{\lambda_{k}} P_{k}(2)+\cdots+\frac{\mu}{\lambda_{k}} P_{k}\left(s_{k}-1\right)\right\} \\
\text { which implies } P_{k}\left(Q_{k}\right)=\frac{\mu}{\lambda_{k}}\left\{P_{k}(0)+P_{k}(1)+P_{k}(2)+\cdots+P_{k}\left(s_{k}\right)\right\}
\end{gathered}
$$


Now replacing the value of $P_{k}(2), P_{k}(3), \ldots, P_{k}\left(s_{k}\right)$ by using Eq. (7) and the value of $P_{k}(1)$ from Eq. (1) we have

$$
\begin{gathered}
P_{k}\left(Q_{k}\right)=\frac{\mu}{\lambda_{k}}\left\{P_{k}(0)\left(1+\frac{\mu}{\lambda_{k}}\right)+\left(1+\frac{\mu}{\lambda_{k}}\right) P_{k}(1)+\left(1+\frac{\mu}{\lambda_{k}}\right)^{2} P_{k}(1)+\cdots+\left(1+\frac{\mu}{\lambda_{k}}\right)^{s_{k}-1} P_{k}(1)\right\} \\
=\frac{\mu}{\lambda_{k}}\left[P_{k}(0)\left(1+\frac{\mu}{\lambda_{k}}\right)+\frac{\mu}{\lambda_{k}} P_{k}(0)\left\{\left(1+\frac{\mu}{\lambda_{k}}\right)+\left(1+\frac{\mu}{\lambda_{k}}\right)^{2}+\cdots+\left(1+\frac{\mu}{\lambda_{k}}\right)^{s_{k}-1}\right\}\right] \\
=P_{k}(0) \frac{\mu}{\lambda_{k}}\left[\left(1+\frac{\mu}{\lambda_{k}}\right)+\frac{\mu}{\lambda_{k}}\left\{\frac{\left(1+\frac{\mu}{\lambda_{k}}\right)-\left(1+\frac{\mu}{\lambda_{k}}\right)^{s_{k}}}{1-1-\frac{\mu}{\lambda_{k}}}\right\}\right]
\end{gathered}
$$$$
\text { [By using formula } \sum_{n=a}^{b} q^{n}=\frac{q^{a}-q^{b+1}}{1-q} \text { ] }
$$$$
=P_{k}(0) \frac{\mu}{\lambda_{k}}\left(1+\frac{\mu}{\lambda_{k}}\right)^{s_{k}}
$$

Recursive solution of equation (5) for $P_{k}\left(Q_{k}+1\right), P_{k}\left(Q_{k}+2\right), \ldots, P_{k}\left(Q_{k}+s_{k}\right)$

Again from Eq. (5) we have

$$
\begin{gathered}
\qquad \lambda_{k} P_{k}(j)=\lambda_{k} P_{k}(j+1)+\mu P_{k}\left(j-Q_{k}\right) \\
\text { which implies } P_{k}(j+1)=P_{k}(j)-\frac{\mu}{\lambda_{k}} P_{k}\left(j-Q_{k}\right) \\
\text { Let } j=Q_{k} \text { which yields } \\
P_{k}\left(Q_{k}+1\right)=P_{k}\left(Q_{k}\right)-\frac{\mu}{\lambda_{k}} P_{k}(0)
\end{gathered}
$$

Now putting the value of $P_{k}\left(Q_{k}\right)=P_{k}(0) \frac{\mu}{\lambda_{k}}\left(1+\frac{\mu}{\lambda_{k}}\right)^{s_{k}}$ in the above equation we have

$$
P_{k}\left(Q_{k}+1\right)=P_{k}(0) \frac{\mu}{\lambda_{k}}\left\{\left(1+\frac{\mu}{\lambda_{k}}\right)^{s_{k}}-1\right\}
$$

Again let $j=Q_{k}+1$ which yields

$$
P_{k}\left(Q_{k}+2\right)=P_{k}\left(Q_{k}+1\right)-\frac{\mu}{\lambda_{k}} P_{k}(1)
$$

Replacing the value of $P_{k}\left(Q_{k}+1\right)=P_{k}(0) \frac{\mu}{\lambda_{k}}\left\{\left(1+\frac{\mu}{\lambda_{k}}\right)^{s_{k}}-1\right\}$ and $P_{k}$ (1) from Eq. (1) to the above equation we have 


$$
\begin{gathered}
P_{k}\left(Q_{k}+2\right)=P_{k}(0) \frac{\mu}{\lambda_{k}}\left\{\left(1+\frac{\mu}{\lambda_{k}}\right)^{s_{k}}-1\right\}-\frac{\mu}{\lambda_{k}}\left\{\frac{\mu}{\lambda_{k}} P_{k}(0)\right\} \\
=P_{k}(0) \frac{\mu}{\lambda_{k}}\left(1+\frac{\mu}{\lambda_{k}}\right)^{s_{k}}-P_{k}(0) \frac{\mu}{\lambda_{k}}-\frac{\mu}{\lambda_{k}}\left\{\frac{\mu}{\lambda_{k}} P_{k}(0)\right\} \\
=P_{k}(0) \frac{\mu}{\lambda_{k}}\left(1+\frac{\mu}{\lambda_{k}}\right)^{s_{k}}-P_{k}(0) \frac{\mu}{\lambda_{k}}\left(1+\frac{\mu}{\lambda_{k}}\right) \\
=P_{k}(0) \frac{\mu}{\lambda_{k}}\left\{\left(1+\frac{\mu}{\lambda_{k}}\right)^{s_{k}}-\left(1+\frac{\mu}{\lambda_{k}}\right)\right\}
\end{gathered}
$$

Again from the recursive equation mentioned above we have

$$
\begin{gathered}
P_{k}\left(Q_{k}+s_{k}\right)=P_{k}\left(Q_{k}\right)-\frac{\mu}{\lambda_{k}}\left\{P_{k}(0)+P_{k}(1)+P_{k}(2)+\cdots+P_{k}\left(s_{k}-1\right)\right\} \\
=P_{k}(0) \frac{\mu}{\lambda_{k}}\left(1+\frac{\mu}{\lambda_{k}}\right)^{s_{k}}-\frac{\mu}{\lambda_{k}}\left\{P_{k}(0)+\frac{\mu}{\lambda_{k}} P_{k}(0)+\left(1+\frac{\mu}{\lambda_{k}}\right) \frac{\mu}{\lambda_{k}} P_{k}(0)+\cdots+\left(1+\frac{\mu}{\lambda_{k}}\right)^{s_{k}-2} \frac{\mu}{\lambda_{k}} P_{k}(0)\right\} \\
=P_{k}(0) \frac{\mu}{\lambda_{k}}\left(1+\frac{\mu}{\lambda_{k}}\right)^{s_{k}}-P_{k}(0) \frac{\mu}{\lambda_{k}}\left\{1+\frac{\mu}{\lambda_{k}}+\left(1+\frac{\mu}{\lambda_{k}}\right) \frac{\mu}{\lambda_{k}}+\cdots+\left(1+\frac{\mu}{\lambda_{k}}\right)^{s_{k}-2} \frac{\mu}{\lambda_{k}}\right\} \\
=P_{k}(0) \frac{\mu}{\lambda_{k}}\left(1+\frac{\mu}{\lambda_{k}}\right)^{s_{k}}-P_{k}(0) \frac{\mu}{\lambda_{k}}\left[1+\frac{\mu}{\lambda_{k}}+\frac{\mu}{\lambda_{k}}\left\{\left(1+\frac{\mu}{\lambda_{k}}\right)+\cdots+\left(1+\frac{\mu}{\lambda_{k}}\right)^{s_{k}-2}\right\}\right] \\
=P_{k}(0) \frac{\mu}{\lambda_{k}}\left(1+\frac{\mu}{\lambda_{k}}\right)^{s_{k}}-P_{k}(0) \frac{\mu}{\lambda_{k}}\left[\left(1+\frac{\mu}{\lambda_{k}}\right)+\frac{\mu}{\lambda_{k}}\left\{\frac{\left.\left(1+\frac{\mu}{\lambda_{k}}\right)-\left(1+\frac{\mu}{\lambda_{k}}\right)^{s_{k}-1}\right)}{1-1-\frac{\mu}{\lambda_{k}}}\right\}\right] \\
=P_{k}(0) \frac{\mu}{\lambda_{k}}\left\{\left(1+\frac{\mu}{\lambda_{k}}\right)^{s_{k}}-\left(1+\frac{\mu}{\lambda_{k}}\right)^{s_{k}-1}\right\}
\end{gathered}
$$

\section{Computation of $\boldsymbol{P}_{\boldsymbol{k}}(0)$ from the relation of $\sum_{j=0}^{Q_{k}+s_{k}} P_{k}(j)=1$}

We have

$$
\sum_{j=0}^{Q_{k}+s_{k}} P_{k}(j)=P_{k}(0)+\sum_{j=1}^{s_{k}} P_{k}(j)+\sum_{j=s_{k}+1}^{Q_{k}} P_{k}(j)+\sum_{j=Q_{k}+1}^{Q_{k}+s_{k}} P_{k}(j)=1
$$

Here

$$
\sum_{i=1}^{s_{k}} P_{k}(j)=P_{k}(0) \frac{\mu}{\lambda_{k}}\left\{\sum_{j=1}^{s_{k}}\left(1+\frac{\mu}{\lambda_{k}}\right)^{j-1}\right\}
$$




$$
\begin{gathered}
=P_{k}(0) \frac{\mu}{\lambda_{k}}\left\{\left(1+\frac{\mu}{\lambda_{\mathrm{k}}}\right)^{0}+\left(1+\frac{\mu}{\lambda_{k}}\right)^{1}+\cdots+\left(1+\frac{\mu}{\lambda_{k}}\right)^{s_{k}-1}\right\} \\
=P_{k}(0) \frac{\mu}{\lambda_{k}}\left\{\frac{\left(1+\frac{\mu}{\lambda_{k}}\right)^{0}-\left(1+\frac{\mu}{\lambda_{k}}\right)^{s_{k}}}{1-1-\frac{\mu}{\lambda_{k}}}\right\} \\
{\left[\text { By using formula } \sum_{n=a}^{b} q^{n}=\frac{q^{a}-q^{b+1}}{1-q}\right]} \\
=-P_{k}(0)\left\{1-\left(1+\frac{\mu}{\lambda_{k}}\right)^{s_{k}}\right\}
\end{gathered}
$$

Again

$$
\begin{gathered}
\sum_{j=Q_{k}+1}^{Q_{k}+s_{k}} P_{k}(j)=P_{k}(0) \frac{\mu}{\lambda_{k}} \sum_{j=Q_{k}+1}^{Q_{k}+s_{k}}\left\{\left(1+\frac{\mu}{\lambda_{k}}\right)^{s_{k}}-\left(1+\frac{\mu}{\lambda_{k}}\right)^{j-Q_{k}-1}\right\} \\
=P_{k}(0) \frac{\mu}{\lambda_{k}} \sum_{j=Q_{k}+1}^{Q_{k}+s_{k}}\left\{\left(1+\frac{\mu}{\lambda_{k}}\right)^{s_{k}}\right\}-P_{k}(0) \frac{\mu}{\lambda_{k}} \sum_{j=Q_{k}+1}^{Q_{k}+s_{k}}\left\{\left(1+\frac{\mu}{\lambda_{k}}\right)^{j-Q_{k}-1}\right\} \\
=P_{k}(0) \frac{\mu}{\lambda_{k}} \sum_{j=Q_{k}+1}^{Q_{k}+s_{k}}\left\{\left(1+\frac{\mu}{\lambda_{k}}\right)^{s_{k}}\right\}-P_{k}(0) \frac{\mu}{\lambda_{k}}\left\{\left(1+\frac{\mu}{\lambda_{k}}\right)^{0}+\left(1+\frac{\mu}{\lambda_{k}}\right)^{1}+\cdots+\left(1+\frac{\mu}{\lambda_{k}}\right)^{s_{k}-1}\right\} \\
=P_{k}(0) \frac{\mu}{\lambda_{k}} \sum_{j=Q_{k}+1}^{Q_{k}+s_{k}}\left\{\left(1+\frac{\mu}{\lambda_{k}}\right)^{s_{k}}\right\}+P_{k}(0)\left\{1-\left(1+\frac{\mu}{\lambda_{k}}\right)^{s_{k}}\right\}
\end{gathered}
$$

Now replacing the expressions to the below equation

$$
P_{k}(0)+\sum_{j=1}^{s_{k}} P_{k}(j)+\sum_{j=s_{k}+1}^{Q_{k}} P_{k}(j)+\sum_{j=Q_{k}+1}^{Q_{k}+s_{k}} P_{k}(j)=1
$$

we finally have

$$
\begin{aligned}
P_{k}(0)-P_{k}(0)\{1 & \left.-\left(1+\frac{\mu}{\lambda_{k}}\right)^{s_{k}}\right\}+P_{k}(0) \frac{\mu}{\lambda_{k}} \sum_{j=s_{k}+1}^{Q_{k}}\left\{\left(1+\frac{\mu}{\lambda_{k}}\right)^{s_{k}}\right\}+P_{k}(0) \frac{\mu}{\lambda_{k}} \sum_{j=Q_{k}+1}^{Q_{k}+s_{k}}\left\{\left(1+\frac{\mu}{\lambda_{k}}\right)^{s_{k}}\right\} \\
+ & P_{k}(0)\left\{1-\left(1+\frac{\mu}{\lambda_{k}}\right)^{s_{k}}\right\}=1
\end{aligned}
$$

which yields 


$$
P_{k}(0)\left\{1+\sum_{j=s_{k}+1}^{Q_{k}+s_{k}}\left(1+\frac{\mu}{\lambda_{k}}\right)^{s_{k}} \frac{\mu}{\lambda_{k}}\right\}=1
$$

After rearranging the above equation, we have

$$
\begin{aligned}
P_{k}(0) & =\frac{1}{1+\sum_{j=s_{k}+1}^{Q_{k}+s_{k}}\left(1+\frac{\mu}{\lambda_{k}}\right)^{s_{k}} \frac{\mu}{\lambda_{k}}} \\
& =\frac{\lambda_{k}}{\lambda_{k}+Q_{k} \mu\left(1+\frac{\mu}{\lambda_{k}}\right)^{s_{k}}}
\end{aligned}
$$

\section{Computation of mean inventory level $\boldsymbol{L}_{k}$}

From queuing system, the mean inventory level in the long run can be derived as

$$
L_{k}=\sum_{j=0}^{Q_{k}+s_{k}} j P_{k}(j)=0 . P_{k}(0)+\sum_{j=1}^{s_{k}} j P_{k}(j)+\sum_{j=s_{k}+1}^{Q_{k}} j P_{k}(j)+\sum_{j=Q_{k}+1}^{Q_{k}+s_{k}} j P_{k}(j)
$$

which yields

$$
L_{k}=\sum_{j=1}^{s_{k}} j P_{k}(j)+\sum_{j=s_{k}+1}^{Q_{k}} j P_{k}(j)+\sum_{j=Q_{k}+1}^{Q_{k}+s_{k}} j P_{k}(j)
$$

Here

$$
\begin{gathered}
\sum_{j=1}^{s_{k}} j P_{k}(j)=P_{k}(0) \sum_{j=1}^{s_{k}} j \frac{\mu}{\lambda_{k}}\left(1+\frac{\mu}{\lambda_{k}}\right)^{j-1} \\
\text { Let, } X=1+\frac{\mu}{\lambda_{k}} \text { we have } \\
\sum_{j=1}^{s_{k}} j P_{k}(j)=P_{k}(0) \sum_{j=1}^{s_{k}} j(X-1) X^{j-1}
\end{gathered}
$$

Again

$$
\begin{gathered}
\sum_{i=s_{k}+1}^{Q_{k}} j P_{k}(j)=\sum_{j=s_{k}+1}^{Q_{k}} j\left(1+\frac{\mu}{\lambda_{k}}\right)^{s_{k}} \frac{\mu}{\lambda_{k}} P_{k}(0) \\
=P_{k}(0) \sum_{j=s_{k}+1}^{Q_{k}} j X^{s_{k}}(X-1)
\end{gathered}
$$

And 


$$
\begin{gathered}
\sum_{t=Q_{k}+1}^{Q_{k}+s_{k}} j P_{k}(j)=P_{k}(0) \frac{\mu}{\lambda_{k}} \sum_{j=Q_{k}+1}^{Q_{k}+s_{k}} j\left\{\left(1+\frac{\mu}{\lambda_{k}}\right)^{s_{k}}-\left(1+\frac{\mu}{\lambda_{k}}\right)^{j-Q_{k}-1}\right\} \\
=P_{k}(0) \sum_{j=Q_{k}+1}^{Q_{k}+s_{k}} j(X-1)\left(X^{s_{k}}-X^{j-Q_{k}-1}\right) \\
=P_{k}(0) \sum_{j=Q_{k}+1}^{Q_{k}+s_{k}} j(X-1) X^{s_{k}}-P_{k}(0) \sum_{j=Q_{k}+1}^{Q_{k}+s_{k}} j(X-1) X^{j-Q_{k}-1} \\
=P_{k}(0) \sum_{j=Q_{k}+1}^{Q_{k}+s_{k}} j(X-1) X^{s_{k}}-P_{k}(0) \sum_{j=Q_{k}+1}^{Q_{k}+s_{k}}\left(j-Q_{k}\right)(X-1) X^{j-Q_{k}-1}-P_{k}(0) \sum_{j=Q_{k}+1}^{Q_{k}+s_{k}} Q_{k}(X-1) X^{j-Q_{k}-1}
\end{gathered}
$$

So finally we have

$$
\begin{aligned}
& L_{k}=\sum_{j=1}^{s_{k}} j P_{k}(j)+\sum_{j=s_{k}+1}^{Q_{k}} j P_{k}(j)+\sum_{j=Q_{k}+1}^{Q_{k}+s_{k}} j P_{k}(j) \\
& =P_{k}(0) \sum_{j=1}^{s_{k}} j(X-1) X^{j-1}+P_{k}(0) \sum_{j=s_{k}+1}^{Q_{k}} j X^{s_{k}}(X-1) \\
& +P_{k}(0) \sum_{j=Q_{k}+1}^{Q_{k}+s_{k}} j(X-1) X^{s_{k}}-P_{k}(0) \sum_{j=Q_{k}+1}^{Q_{k}+s_{k}}\left(j-Q_{k}\right)(X-1) X^{j-Q_{k}-1} \\
& -P_{k}(0) \sum_{j=Q_{k}+1}^{Q_{k}+s_{k}} Q_{k}(X-1) X^{j-Q_{k}-1} \\
& =P_{k}(0) \sum_{j=1}^{s_{k}} j(X-1) X^{j-1}+P_{k}(0) \sum_{j=s_{k}+1}^{Q_{k}+s_{k}} j X^{s_{k}}(X-1) \\
& -P_{k}(0) \sum_{j=Q_{k}+1}^{Q_{k}+s_{k}} Q_{k}(X-1) X^{j-Q_{k}-1}-P_{k}(0) \sum_{j=Q_{k}+1}^{Q_{k}+s_{k}}\left(j-Q_{k}\right)(X-1) X^{j-Q_{k}-1} \\
& =P_{k}(0) \sum_{j=s_{k}+1}^{Q_{k}+s_{k}} j X^{s_{k}}(X-1)-P_{k}(0) \sum_{j=Q_{k}+1}^{Q_{k}+s_{k}} Q_{k}(X-1) X^{j-Q_{k}-1} \\
& {\left[\text { Here } \sum_{j=1}^{s_{k}} j X^{j-1}=\sum_{j=Q_{k}+1}^{Q_{k}+s_{k}}\left(j-Q_{k}\right) X^{j-Q_{k}-1}=1+2 X+3 X^{2}+\cdots \cdots+s_{k} X^{s_{k}-1}\right]}
\end{aligned}
$$


$=P_{k}(0) \sum_{j=s_{k}+1}^{Q_{k}+s_{k}} j X^{s_{k}}(X-1)-P_{k}(0) Q_{k}(X-1) \frac{1-X^{s_{k}}}{1-X}$

Here

$$
\begin{aligned}
& \sum_{t=Q_{k}+1}^{Q_{k}+s_{k}} X^{j-Q_{k}-1}=1+X+X^{2}+\cdots \cdots+X^{s_{k}-1}=\frac{1-X^{s_{k}}}{1-X} \\
& {\left[\begin{array}{c}
\text { By using formula } s=a\left(\frac{1-x^{n}}{1-x}\right) \\
\text { for series } s=a+a x+a x^{2}+\cdots+a x^{n-1}
\end{array}\right]} \\
& =P_{k}(0)(X-1) X^{s_{k}}\left\{\sum_{j=1}^{Q_{k}+s_{k}} j-\sum_{j=1}^{s_{k}} j\right\}+P_{k}(0) Q_{k}-X^{s_{k}} P_{k}(0) Q_{k} \\
& =P_{k}(0)(X-1) X^{s_{k}}\left\{\frac{\left(Q_{k}+s_{k}\right)\left(Q_{k}+s_{k}+1\right)}{2}-\frac{s_{k}\left(s_{k}+1\right)}{2}\right\}+P_{k}(0) Q_{k}-X^{s_{k}} P_{k}(0) Q_{k} \\
& {\left[\begin{array}{c}
\text { By using formula } \\
\sum_{k=1}^{n} k=\frac{n(n+1)}{2}
\end{array}\right]} \\
& =P_{k}(0)(X-1) X^{s_{k}}\left\{\frac{\left(Q_{k}+s_{k}\right)\left(Q_{k}+s_{k}+1\right)}{2}-\frac{s_{k}\left(s_{k}+1\right)}{2}\right\}+P_{k}(0) Q_{k}-X^{s_{k}} P_{k}(0) Q_{k} \\
& =P_{k}(0) X^{s_{k}}\left\{\frac{(X-1)}{2}\left(Q_{k}^{2}+Q_{k}+2 Q_{k} s_{k}\right)-Q_{k}\right\}+P_{k}(0) Q_{k} \\
& =P_{k}(0)\left(1+\frac{\mu}{\lambda_{k}}\right)^{s_{k}}\left\{\frac{\mu}{2 \lambda_{k}}\left(Q_{k}^{2}+Q_{k}+2 Q_{k} s_{k}\right)-Q_{k}\right\}+P_{k}(0) Q_{k}
\end{aligned}
$$

Journal of Industrial Engineering and Management, 2021 (www.jiem.org)

\section{(c) (1) (\$)}

Article's contents are provided on an Attribution-Non Commercial 4.0 Creative commons International License. Readers are allowed to copy, distribute and communicate article's contents, provided the author's and Journal of Industrial Engineering and Management's names are included. It must not be used for commercial purposes. To see the complete license contents, please visit https://creativecommons.org/licenses/by-nc/4.0/. 